\title{
Proteomic and Bioinformatics Analyses of Mouse Liver Microsomes
}

\author{
Fang Peng, ${ }^{1}$ Xianquan Zhan, ${ }^{1}$ Mao-Yu Li, ${ }^{1}$ Fan Fang, ${ }^{1}$ Guoqing Li, ${ }^{1,2}$ \\ Cui Li, ${ }^{1}$ Peng-Fei Zhang, ${ }^{1}$ and Zhuchu Chen ${ }^{1}$ \\ ${ }^{1}$ Key Laboratory of Cancer Proteomics of Chinese Ministry of Health, Xiangya Hospital, Central South University, Hunan, \\ Changsha 410008, China \\ ${ }^{2}$ Department of Biology, School of Pharmacy and Life Science, University of South China, Hengyang 421001, China
}

Correspondence should be addressed to Xianquan Zhan, yjzhan2011@gmail.com and Zhuchu Chen, tcbl@xysm.net

Received 28 July 2011; Revised 9 November 2011; Accepted 20 November 2011

Academic Editor: Visith Thongboonkerd

Copyright (๑) 2012 Fang Peng et al. This is an open access article distributed under the Creative Commons Attribution License, which permits unrestricted use, distribution, and reproduction in any medium, provided the original work is properly cited.

\begin{abstract}
Microsomes are derived mostly from endoplasmic reticulum and are an ideal target to investigate compound metabolism, membrane-bound enzyme functions, lipid-protein interactions, and drug-drug interactions. To better understand the molecular mechanisms of the liver and its diseases, mouse liver microsomes were isolated and enriched with differential centrifugation and sucrose gradient centrifugation, and microsome membrane proteins were further extracted from isolated microsomal fractions by the carbonate method. The enriched microsome proteins were arrayed with two-dimensional gel electrophoresis (2DE) and carbonate-extracted microsome membrane proteins with one-dimensional gel electrophoresis (1DE). A total of $1832 \mathrm{DE}$-arrayed proteins and $991 \mathrm{DE}$-separated proteins were identified with tandem mass spectrometry. A total of 259 nonredundant microsomal proteins were obtained and represent the proteomic profile of mouse liver microsomes, including 62 definite microsome membrane proteins. The comprehensive bioinformatics analyses revealed the functional categories of those microsome proteins and provided clues into biological functions of the liver. The systematic analyses of the proteomic profile of mouse liver microsomes not only reveal essential, valuable information about the biological function of the liver, but they also provide important reference data to analyze liver disease-related microsome proteins for biomarker discovery and mechanism clarification of liver disease.
\end{abstract}

\section{Introduction}

The liver, a vital organ, has a wide range of physiological functions and plays a major role in metabolism, biosynthesis, and chemical neutralizing. Liver diseases, such as viral hepatitis and liver cancer, pose a worldwide public health challenge. The Human Liver Proteome Project (HLPP) was launched in 2002 to better understand molecular liver functions and diseases, and liver proteome expression profile is one of the major parts of HLPP [1]. Because of the complexity, no single proteomic analysis strategy can sufficiently address all components of a proteome. Analysis of the subcellular proteome would provide insight into the functions of a given tissue or cell line. Subcellular proteomics reduces the complexity of a proteome $[2,3]$, detects some low-abundance proteins, and offers more detailed information that would contribute to the understanding of the function of the entire proteome.

Microsomes are composed primarily of closed sacs of membrane called vesicles that are derived mostly from endoplasmic reticulum (ER). As for liver, in addition to components of the protein secretary pathway, microsomes contain a multitude of proteins that are involved in lipid/lipoprotein biosynthesis and drug metabolism. The liver microsome is an ideal way to study the metabolism of compounds, the functional properties of membranebound enzymes, lipid-protein interactions, and drug-drug interactions $[4,5]$. The proteomic profiling of the microsomes combined with bioinformatics analysis can reveal more essential information about the biological function of the liver. The main goal of this study was to systematically 
identify the protein components of the liver microsomes, to conduct the functional annotation with bioinformatics analysis, and to provide insight into the biological functions of the liver.

Two-dimensional gel electrophoresis (2DE) is one of the most widespread techniques for the proteomic profiling of soluble proteins and visualizes isoforms and posttranslational modifications in a proteome $[6,7]$. Membrane proteins, however, are less amenable to solubilization in protein extraction buffers and are also susceptible to precipitation during isoelectric focusing (IEF) because of their hydrophobicity and alkaline $\mathrm{pH}$ value. One study showed that the analytical performance of one-dimensional gel electrophoresis (1DE) that separates endoplasmic reticulum membrane proteins is incomparably greater than that of $2 \mathrm{DE}$ [8]. Other studies $[7,9]$ demonstrated that the proteomic analysis of subcellular organelles, such as microsomes that contain a considerable number of highly hydrophobic membrane proteins, should be performed by combining $1 \mathrm{DE}$ and 2DE.

Although many of microsome proteins have been studied, many more remain to be isolated and characterized. With the improvement of current methodologies and experimental techniques, more proteomic data will be obtained. Also, biological interpretation of proteomic data and extracting biological knowledge are essential to further understanding liver function.

In our study, 2DE was first used to array the isolated microsome proteins of the liver. Because of the low performance of $2 \mathrm{DE}$ in separating membrane proteins [10] and the high efficiency of the carbonate procedure in separating membrane proteins $[11,12]$, the membrane proteins from $\mathrm{Na}_{2} \mathrm{CO}_{3}$-treated microsomes were separated by $1 \mathrm{DE}$. Moreover, bioinformatics analysis of microsome proteomic data was performed to discover biological roles of the proteins. The results showed that the combination of $1 \mathrm{DE}$ and $2 \mathrm{DE}$ was more efficient for analyzing microsomes. Bioinformatics analysis can provide a valuable molecular basis to interpret the mechanisms underlying microsome biological functions and give insight into the biological function of the liver at the level of microsomes.

\section{Material and Methods}

2.1. Animals. Male C57 mice (9 weeks old) were purchased from the Experimental Animal Center of Central South University (Changsha, China). The mice were starved overnight for liver subcellular fractionation. All experiments were performed with the approval of the institutional ethics committee on animal research.

\subsection{Preparation, Validation, and 2DE Analysis of Microsomes}

2.2.1. Preparation of Microsomes. Microsome apparatus-rich fractions were prepared from mice livers with differential centrifugation and sucrose gradient centrifugation as described [13]. Mice livers (approximately $10 \mathrm{~g}$ each) were drained of blood, minced thoroughly with scalpels, and transferred to $50 \mathrm{~mL}$ of chilled homogenization medium $(0.25 \mathrm{M}$ sucrose, $\mathrm{pH}$ 7.4) for $5-10 \mathrm{~min}$ with occasional stirring. The liquid was decanted and replaced with $50 \mathrm{~mL}$ of fresh homogenization medium followed by homogenization $(30-60 \mathrm{sec}$.$) on a TAMATO homogenizer (1,000 \mathrm{rpm} \times 3$ and $1,500 \mathrm{rpm} \times 3)$. The homogenate was squeezed through a single layer of microcloth and centrifuged $(10 \mathrm{~min}, 1,000 \mathrm{~g}$; HITACHI centrifuge). The supernatant was centrifuged $(30 \mathrm{~min}, 3,000 \mathrm{~g})$, and sequentially centrifuged (30 min, $8,000 \mathrm{~g}$ ) after discarding the sediment. The remainder supernatant was centrifuged ( $30 \mathrm{~min}, 34,000 \mathrm{~g}$ ), carefully decanted, and centrifuged again $(130,000 \mathrm{~g}, 1 \mathrm{~h}$; Beckman Instruments, Palo Alto, CA) to get the "light" microsomes. The pink sediment was gently resuspended with a glass homogenizer in $\sim 7 \mathrm{~mL}$ of $52 \%$ sucrose- $0.1 \mathrm{M} \mathrm{H}_{3} \mathrm{PO}_{4}$ buffer ( $\mathrm{pH}$ 7.1), and the density of sucrose was adjusted to $43.7 \%$. The fraction was placed in one type-70i rotor centrifuge tube; overlayered sequentially with $7 \mathrm{~mL}, 5 \mathrm{~mL}, 5 \mathrm{~mL}$, and $6 \mathrm{~mL}$ of $38.7 \%, 36.0 \%, 33.0 \%$, and $29.0 \%$ sucrose, respectively, and centrifuged $(80,000 \mathrm{~g}, 1 \mathrm{~h})$. The upper four layers of the sucrose gradient were discarded by aspiration, and the bottom layer $(43.7 \%)$ was diluted with two volumes of cold distilled water and centrifuged $(130,000 \mathrm{~g}, 1 \mathrm{~h})$ in a type$70 \mathrm{i}$ rotor to get the "heavy" microsomes. The pellets, light and heavy microsomes, were suspended in $3 \mathrm{~mL}$ of $0.25 \mathrm{M}$ sucrose $(\mathrm{pH} 7.0)$ and combined. The mixture was diluted to $14 \mathrm{~mL}$ with $0.25 \mathrm{M}$ sucrose containing $\mathrm{CsCl}$ with its final concentration of $0.015 \mathrm{M}$. The suspension was layered into an equal volume of $1.3 \mathrm{M}$ sucrose $/ 0.015 \mathrm{M} \mathrm{CsCl}$ and then centrifuged $(240,000 \mathrm{~g}, 1 \mathrm{~h})$ in an SW 55Ti rotor. The rough microsomes were in the pink sediment, and the smooth microsomes were at the interface. The smooth microsomes were diluted with an equal volume of $0.25 \mathrm{M}$ sucrose ( $\mathrm{pH} 7.0)$ and centrifuged $(140,000 \mathrm{~g}, 1 \mathrm{~h})$ in an SW $55 \mathrm{i}$ rotor.

\subsubsection{Detection and Validation of the Purity of Microsomes.} Electron microscopy and Western blotting were used to detect and validate the purity of prepared microsomes. For electron microscope analysis, the prepared microsomes were fixed with $2.5 \%$ glutaraldehyde for $24 \mathrm{~h}$ and $2 \%$ OsO4 for $2 \mathrm{~h}$, dehydrated with alcohol $(50 \%, 70 \%, 90 \%$, and $100 \%$ in turn), and processed into epoxy resin. Thin sections (500 $\AA$ ) were prepared and stained with uranyl acetate and lead citrate then examined with a transmission electron microscope (H-600-1, Hitachi, Japan). For Western blotting analysis, the microsome fractions were lysed $\left(4^{\circ} \mathrm{C} ; 30 \mathrm{~min}\right)$ in lysis buffer $(50 \mathrm{mM}$ Tris-Hcl, $150 \mathrm{mM} \mathrm{NaCl}, 1 \mathrm{mM}$ EDTA, $1 \%$ Triton-X100, and $0.1 \%$ SDS). The protein samples $(50 \mu \mathrm{g})$ were subjected to electrophoresis on SDS-PAGE with $12 \%$ gel and transferred to PVDF membrane (Millipore). The PVDF membranes with proteins were immunoblotted with antibodies to endoplasmin (ER marker), OxPhos complex IV subunit I (mitochondrial marker), catalase (peroxisomal marker), and cadherin (cytoplasmic marker), respectively.

2.2.3. Separation of Microsome Proteins by 2DE. 2DE was performed as described by the manufacturer (Amersham Biosciences). Protein samples $(400 \mu \mathrm{g})$ were diluted to $450 \mu \mathrm{L}$ 
with rehydration solution $(7 \mathrm{~mol} / \mathrm{L}$ urea, $2 \mathrm{~mol} / \mathrm{L}$ thiourea, $0.2 \%$ DTT, $0.5 \%(\mathrm{v} / \mathrm{v}) \mathrm{pH} 3-10$ NL IPG buffer, and trace bromophenol blue) and applied to IPG strips ( $\mathrm{pH} 3-10 \mathrm{NL}$; $24 \mathrm{~cm})$ for rehydration $(14 \mathrm{~h} ; 30 \mathrm{~V})$. Proteins were focused successively $(1 \mathrm{~h}$ at $500 \mathrm{~V}, 1 \mathrm{~h}$ at $1,000 \mathrm{~V}$, and $8.5 \mathrm{~h}$ at $8,000 \mathrm{~V}$ ) to give a total of $68 \mathrm{kVh}$ on an IPGphor. After equilibration, SDS-PAGE was performed with $12 \%$ gel on Ettan DALT II system. Then, the blue silver staining method was used to visualize the protein spots on the $2 \mathrm{DE}$ gels [14].

\section{3. $\mathrm{Na}_{2} \mathrm{CO}_{3}$ Extraction and $1 \mathrm{DE}$ Analysis of Microsome Mem-} brane Proteins. Microsome membrane proteins were further extracted by the carbonate method from isolated microsomal fractions [12]. Microsomal fractions were diluted 50- to 1,000 -fold with $100 \mathrm{mM}$ sodium carbonate ( $\mathrm{pH}$ 11.5; final protein concentration to 0.02 to $1 \mathrm{mg} / \mathrm{mL}$ ), and incubated $\left(0^{\circ} \mathrm{C} ; 30 \mathrm{~min}\right)$ with slow stirring and accompanying sonication for $15 \mathrm{sec}$ at $3-4 \mathrm{~W}$ at $0 \mathrm{~min}, 15 \mathrm{~min}$, and $30 \mathrm{~min}$. The suspensions were centrifuged and decanted, and the membrane pellets were gently rinsed three times with ice-cold distilled water. These pellets were diluted with denaturing sample buffer (5\% mercaptoethanol, $2 \%$ SDS, $0.06 \mathrm{M}$ Tris- $\mathrm{HCl}, \mathrm{pH} 6.8$, and $10 \%$ glycerol), heated $\left(95^{\circ} \mathrm{C}\right.$; $5 \mathrm{~min}$ ), and then subjected to 1D SDS-PAGE with a $12 \%$ gel. Electrophoresis was performed at $80 \mathrm{~V}$ for $20 \mathrm{~min}$, followed by $100 \mathrm{~V}$ for $2 \mathrm{~h}$. Gels were visualized with Coomassie Brilliant Blue G [14].

\subsection{Tandem Mass Spectrometry (MS/MS) \\ Identification of Proteins}

2.4.1. In-Gel Digestion. The proteins contained in the $2 \mathrm{D}$ gel spots and 1D gel bands were subjected to in-gel digestion with trypsin. Gel spots or bands were excised and destained with $100 \mathrm{mM} \mathrm{NH}_{4} \mathrm{HCO}_{3}$ in $50 \%$ acetonitrile (ACN) at room temperature. The proteins were reduced with $10 \mathrm{mM}$ dithiothreitol (DDT) $\left(56^{\circ} \mathrm{C} ; 30 \mathrm{~min}\right)$ and alkylated with $50 \mathrm{mM}$ iodoacetamide in $100 \mathrm{mM} \mathrm{NH}_{4} \mathrm{HCO}_{3}$ (dark, room temperature, $30 \mathrm{~min}$ ). The gel pieces that contained proteins were dried and then incubated in the digestion solution $\left(40 \mathrm{mM} \mathrm{NH}_{4} \mathrm{HCO}_{3}, 9 \% \mathrm{ACN}\right.$, and $20 \mu \mathrm{g} / \mathrm{mL}$ trypsin; $18 \mathrm{~h}$, $\left.37^{\circ} \mathrm{C}\right)$. The tryptic peptides were extracted with $50 \%$ ACN $/ 2.5 \%$ TFA and then dried using a Speed-Vac.

2.4.2. Nanoliquid Chromatography (LC) MS/MS and Protein Identification. The tryptic peptide mixture was fractionated with reverse-phase (RP) high-performance liquid chromatography (HPLC) by using an Ultimate nanoHPLC system (Dionex). Peptide samples were purified and concentrated with a C18-PepMap precolumn and then separated on an analytical C18-PepMap column (75 $\mu \mathrm{m}$ ID $\times 150 \mathrm{~mm}, 100 \AA$ pore size, $3 \mathrm{~mm}$ particle size) at a column flow rate of $300 \mathrm{~nL} / \mathrm{min}$. The ACN gradient (solution A: $0.1 \%$ formic acid, $2 \%$ ACN; solution B: $0.1 \%$ formic acid, $80 \% \mathrm{ACN}$ ) started at $5 \% \mathrm{~B}$ and ended at $70 \% \mathrm{~B}$ in $45 \mathrm{~min}$. Mass spectrometry (MS) and MS/MS data were acquired using a Micromass quadrupole time of flight Micromass spectrometer (Waters). Database searches were carried out with the MASCOT server by using a decoy database (concatenated forward-reverse mouse IPI database, version 3.07; release date June 20, 2005). A mass tolerance of $0.3 \mathrm{Da}$ for both parent (MS) and fragmented (MS/MS) ions, allowance for up to one trypsin miscleavage, variable amino acid modifications consisting of methionine oxidation and cysteine carbamidomethylation were used. MS/MS ion score threshold was determined to produce a false-positive rate less than $5 \%$ for a significant hit $(P<0.05)$. The false-positive rate was calculated with $2 *$ reverse/(reverse + forward) $/ 100$. In the current study, the MS/MS ion score threshold was 23 and a false-positive rate was approximately $3.1 \%$. For all the proteins that were identified with only one peptide, each MS/MS spectrum was checked manually.

2.5. Bioinformatics Analysis of Identified Proteins. Protein annotations were obtained primarily from UniProt 7.0 including accession, entry name, comments such as function, catalytic activity, subcellular location, and similarity. The Cytoscape plugin, Biological Networks Gene Ontology (BinGO), was used to find statistically overrepresented GO categories of the protein dataset. An online tool, WebGestalt (http://bioinfo.vanderbilt.edu/webgestalt/), was used to map target proteins to Kyoto Encyclopedia of Genes and Genomes (KEGG) pathways. The pathway visualization was based on the pathway mapping service provided in KEGG.

\section{Results}

3.1. Characterization and Detection of Liver Microsomes. It was essential to obtain a highly pure fraction to conduct proteomic characterization of microsomes. The purity of prepared microsomes was monitored with electron microscope and Western blotting analysis. A large number of nearly spherical membrane vesicles were visualized with electron microscope without other contaminated organelle compositions (see Supplemental Figure 1(a) in Supplementary Material available online at doi:10.1155/2012/832569). Western blotting analyses showed that, with the standard immunoblotting protocol, the ER marker endoplasmin was enriched in the isolated microsome fractions without the contamination marker (mitochondrial marker OxPhos Complex IV subunit I, peroxisomal marker catalase, and cytoplasmic marker cadherin) being detected (Supplemental Figure 1(b)). The results demonstrated an optimized preparation of microsomes.

3.2. Fractionation and Identification of Microsome Proteins Identified by $2 \mathrm{DE}$ and MS/MS. The $2 \mathrm{DE}$ reference maps display $514 \pm 83$ protein spots $(n=10$ gels). A representative 2DE map of microsome proteins was shown (Figure 1). A total of 183 proteins were identified with ESI-Q-TOF MS/MS from 204 excised gel spots. Those proteins are summarized (Table 1 and Supplemental Table 1), including 2D gel-spot number, IPI number, protein name, predicted TMD, and subcellular location. The microsomal marker proteins such as endoplasmin (Spot 2) and UDP glucuronosyltransferase (Spots 6 and 7) were identified. Those proteins were located 


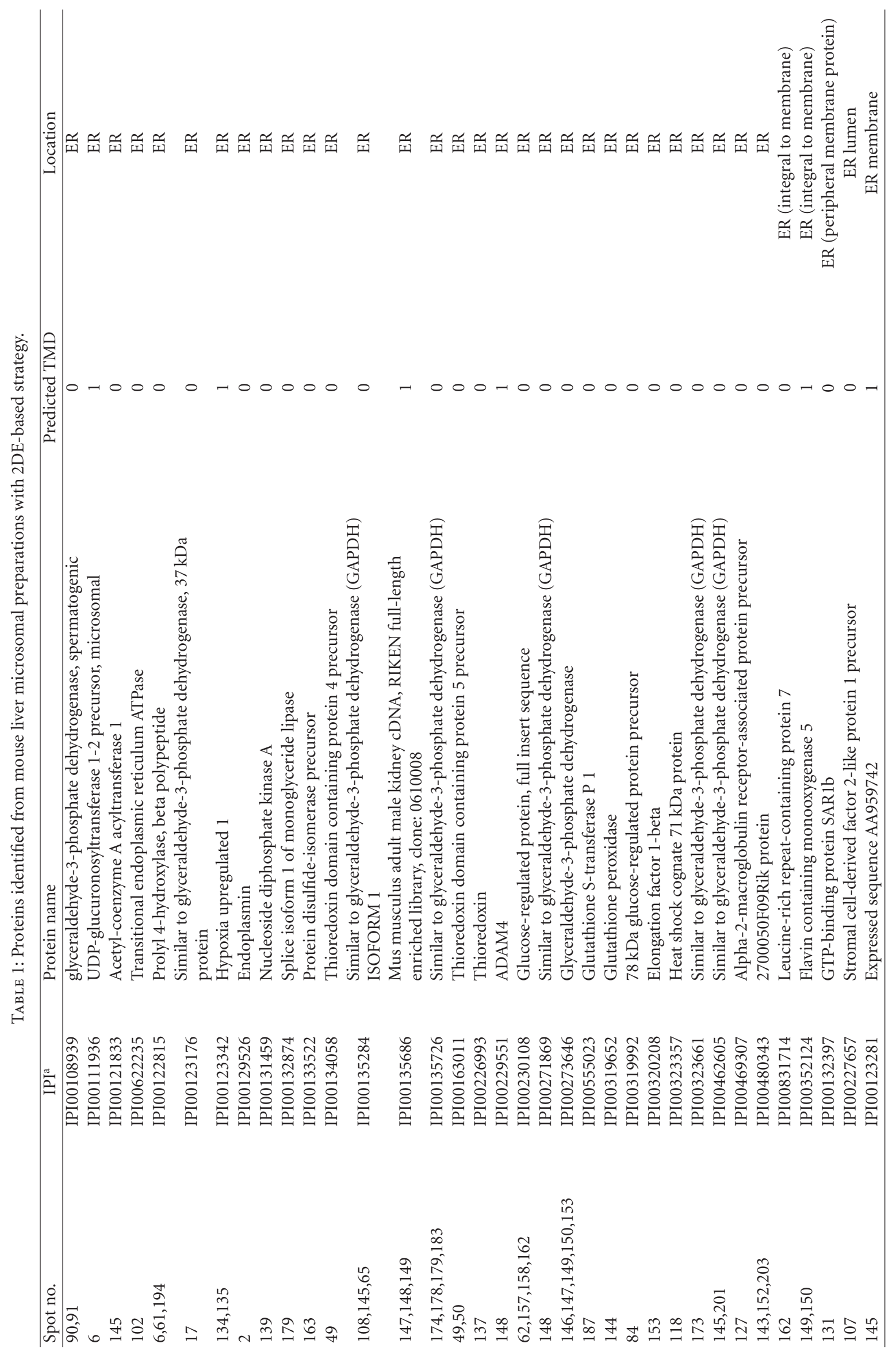




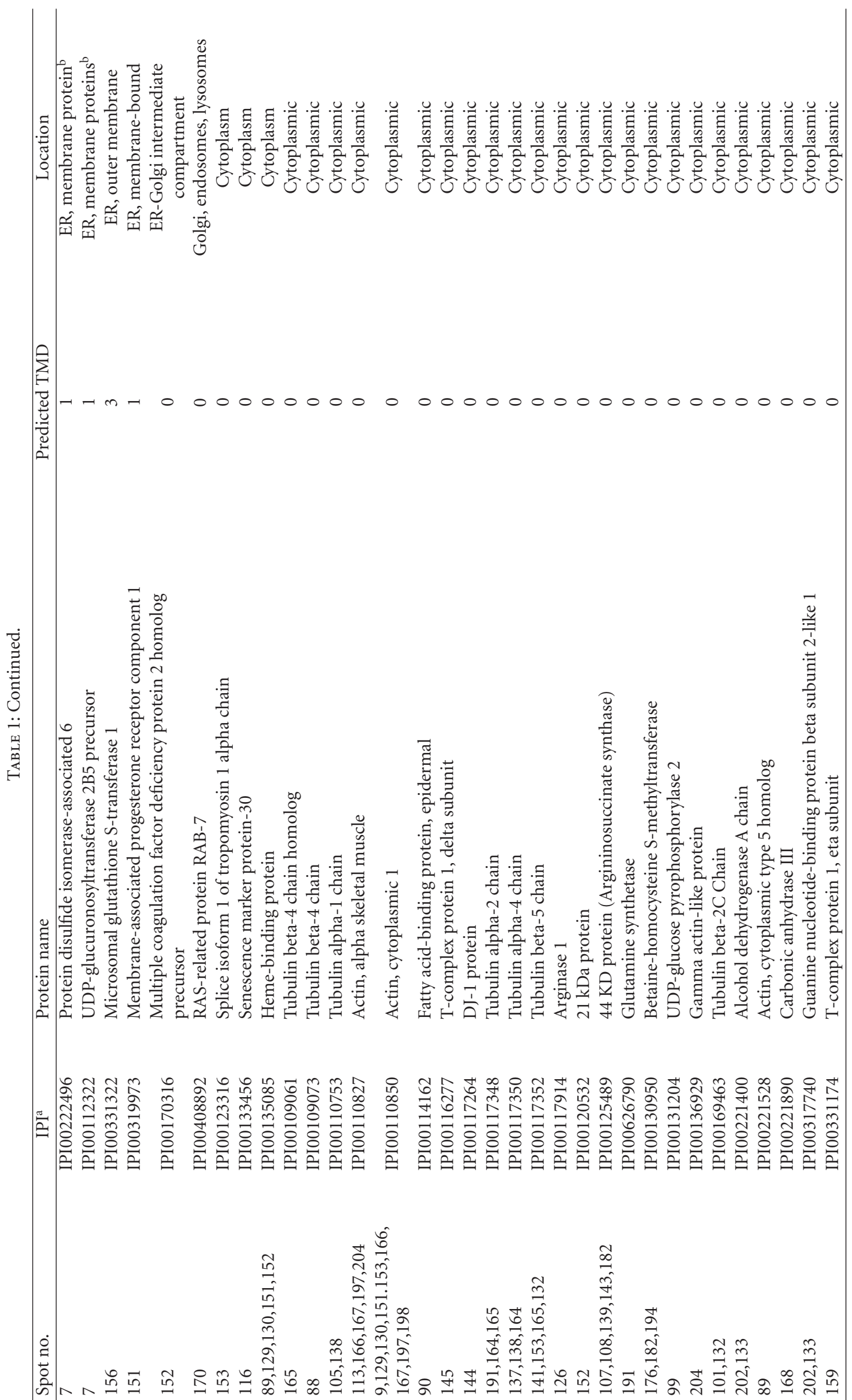




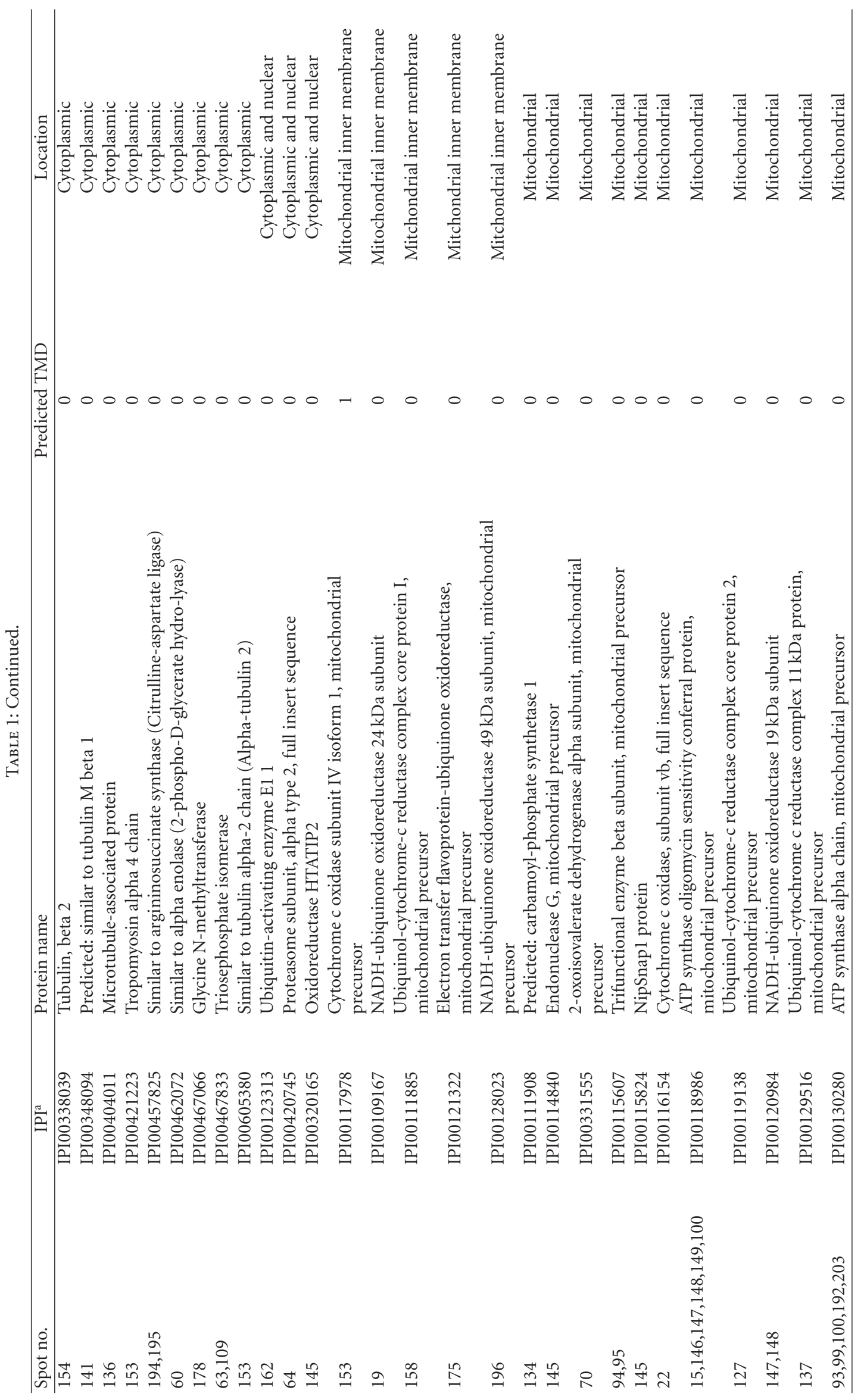




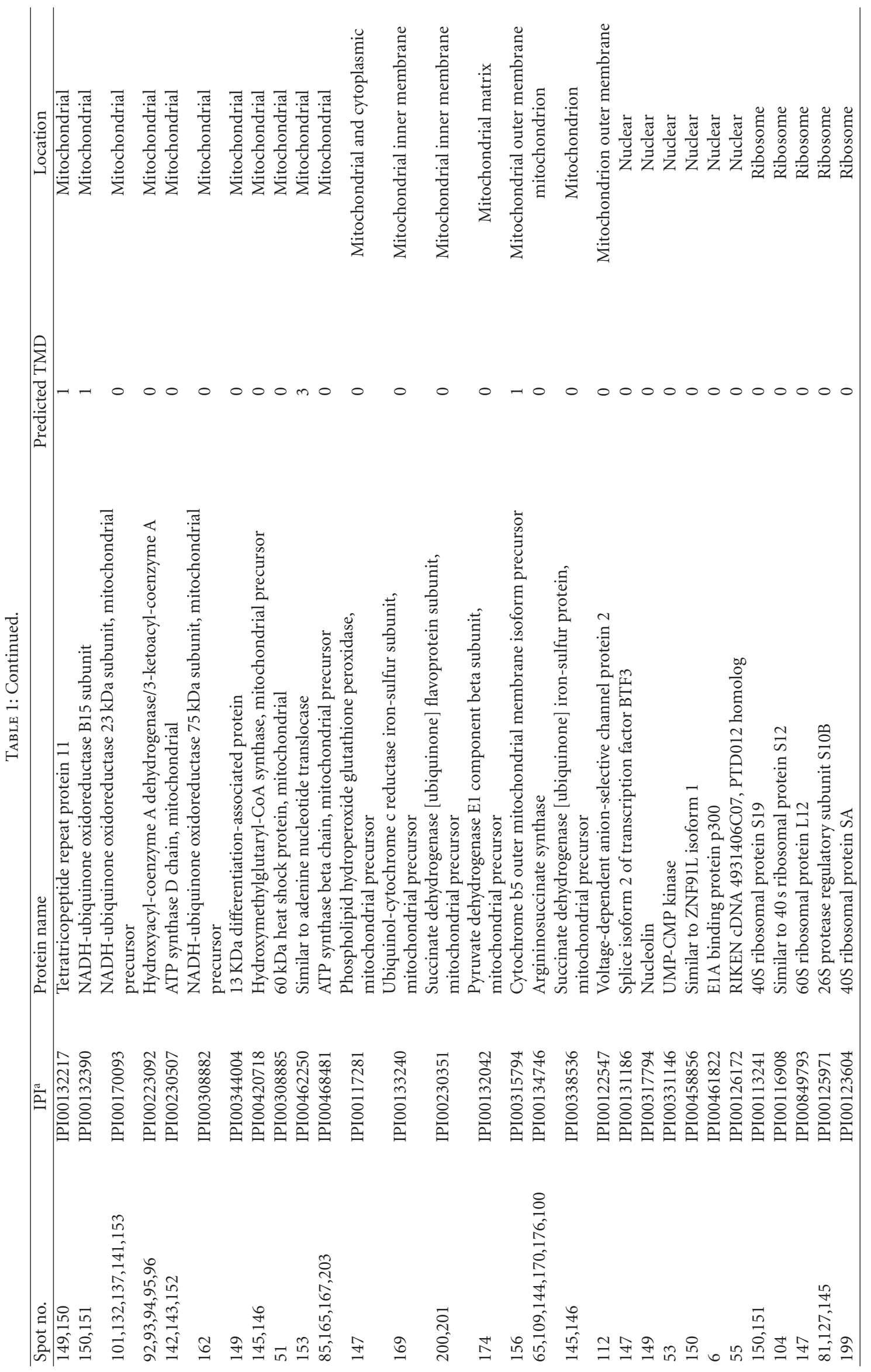




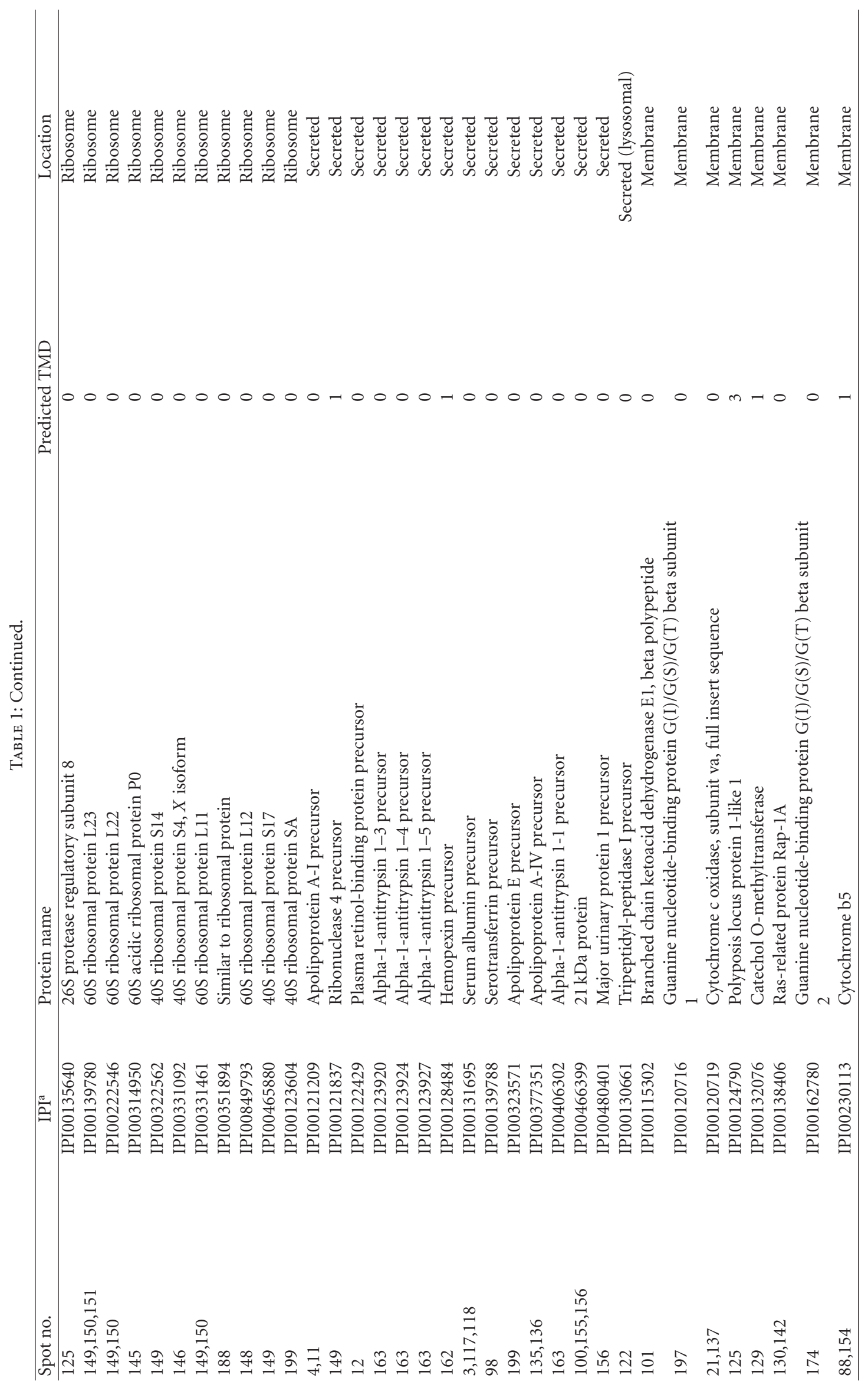




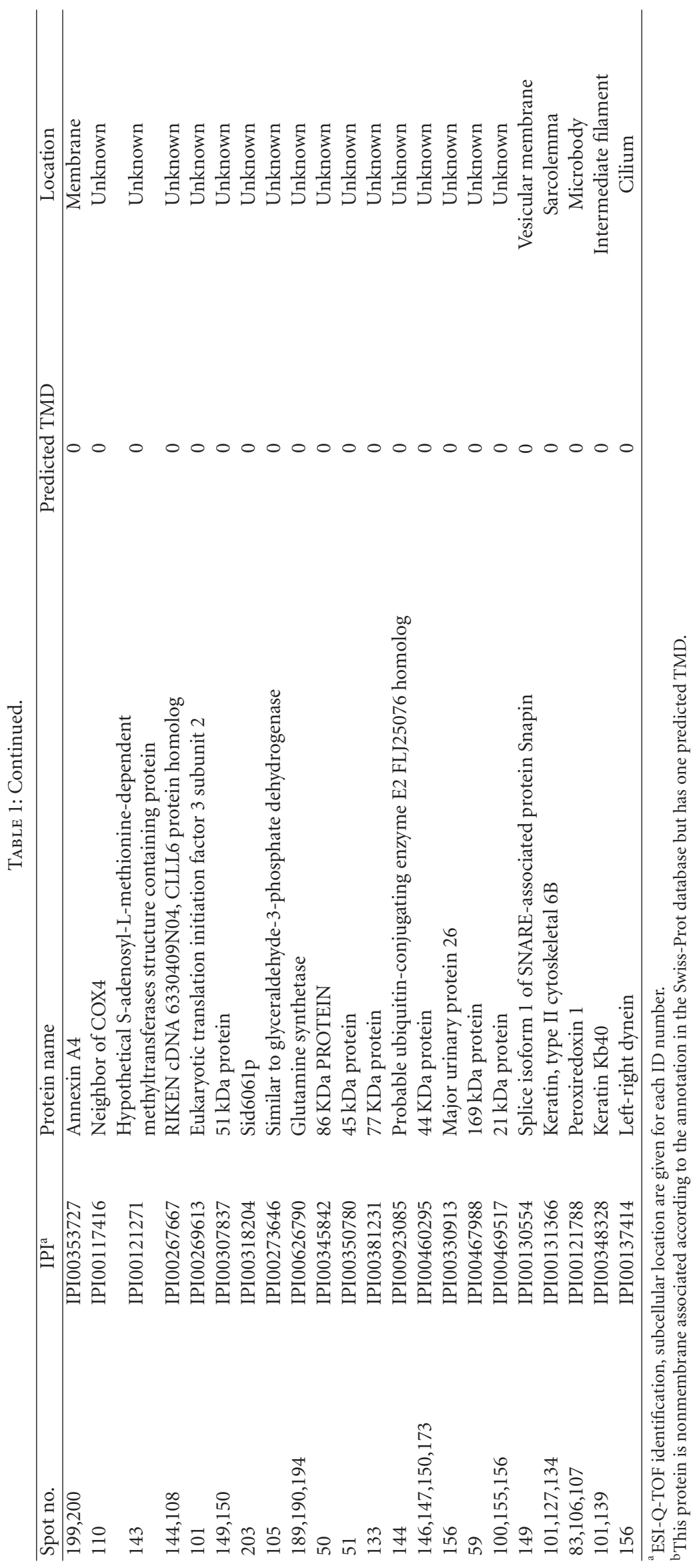




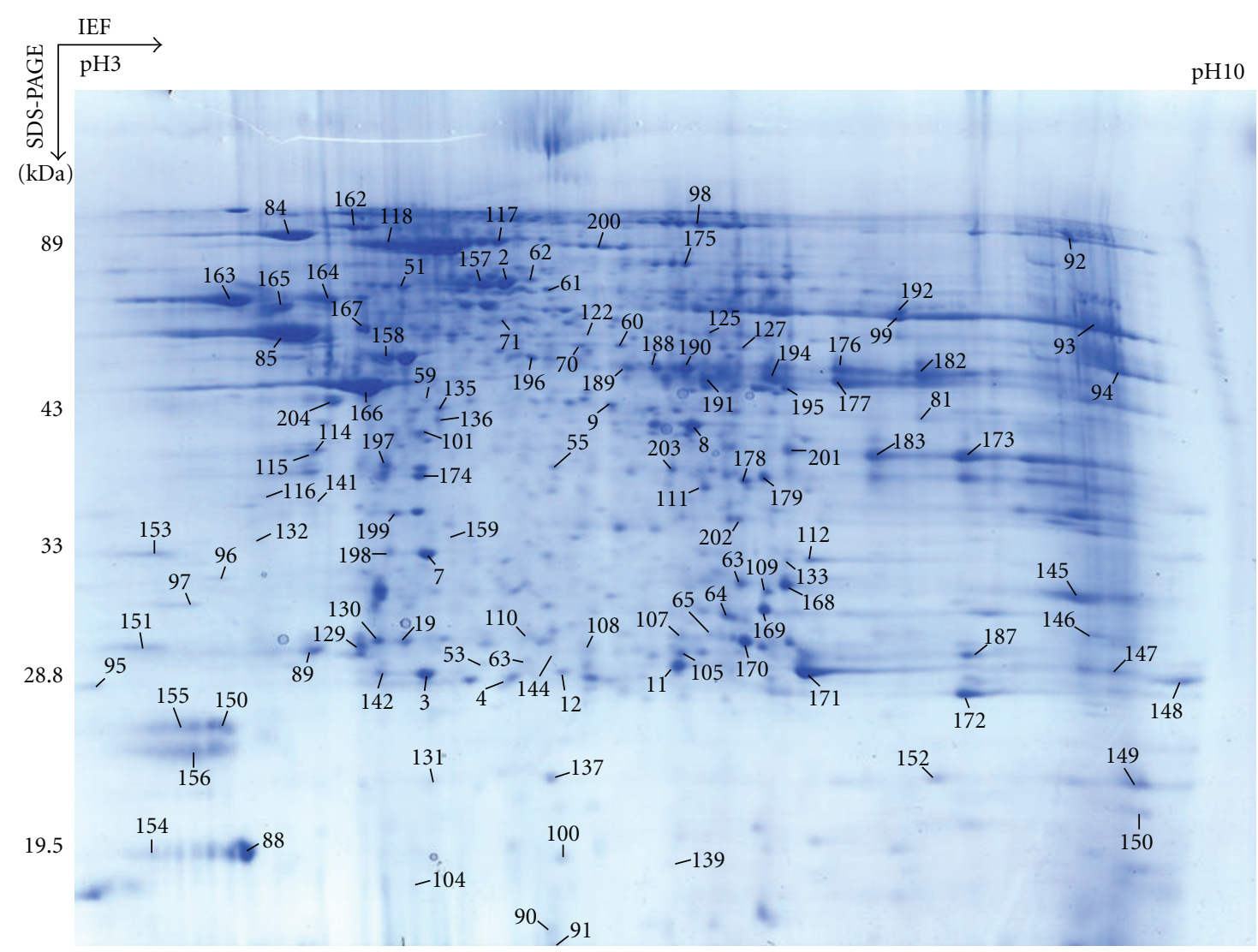

Figure 1: 2DE pattern of mouse liver microsome. Microsomal proteins ( $400 \mu \mathrm{g}$ ) were arrayed by 2DE with IPG strip (pH 3-10 NL; $24 \mathrm{~cm}$ ) and SDS-PAGE with $12 \%$ gel and visualized with blue silver staining method. A total of 204 spots denoted by circles were MS-analyzed.

in different subcellular locations (Table 1) including ER, mitochondrial membrane, cytoplasmic, ribosome, microbody, microsome membrane, nuclear, vesicular membrane, sarcolemma, extracellular space, cilium, ER-Golgi intermediate compartment, and secreted proteins. Supplemental Figure 2 shows the percentage of each group of proteins, according to their subcellular locations, derived from the annotations in the Swiss-Prot database and Gene Ontology: $22 \%$ of proteins $(n=41)$ from ER and Golgi, $11 \%$ of proteins $(n=20)$ from mitochondria and other membranes, $50 \%$ of proteins $(n=91)$ from cytosolic and other soluble proteins, $8 \%$ of secreted proteins $(n=15)$, and $9 \%$ of proteins without unambiguous location $(n=16)$.

\subsection{Fractionation and Identification of Microsomal Membrane} Proteins Identified by $1 D E$ and $M S / M S$. The $\mathrm{Na}_{2} \mathrm{CO}_{3}$-treated microsome membrane proteins were separated on SDSPAGE gels and visualized with Coomassie brilliant blue staining (Figure 2(a)). A total of 99 proteins (Table 2 and Supplemental Table 2) was identified with electrospray ionization(ESI-) Q-TOF MS/MS from 17 gel bands (Figure 2(a)). Those proteins were derived from the ER, type I/II membrane proteins, integral membrane proteins, major histocompatibility complex class I protein, ER-Golgi intermediate compartment, mitochondrial membrane, nuclear, cytoplasm, microbody, sarcolemma, and secreted and unknown proteins (Table 2). Those membrane proteins were classified into three categories (Figure 2(b)): (a) proteins with known membrane associations (55\%; $n=54$ ), (b) putative membrane proteins $(5 \% ; n=5)$, and (c) other proteins $(40 \% ; n=40)$. Those identified proteins were categorized according to the reported annotation in the UniProt database (http://www.uniprot.org/) and predictions for transmembrane regions (http://www.cbs.dtu.dk/services/TMHMM/). Of the 99 proteins, $59(60 \%)$ were described as "membraneassociated" proteins (category (a) and (b)), including ERcharacteristic proteins (cytochromes P-450 and b5, calnexin, integral membrane enzymes such as NADPH-cytochrome c reductase, and microsomal glutathione S-transferase 1).

Hydrophobicity is an important characteristic of a membrane protein. The grand average of hydropathy (GRAVY) scores $(>-0.4)$ (http://us.expasy.org/tools/protparam.html) is an index to evaluate the hydrophobic status of a protein, indicates a hydrophobic protein, and suggests a membrane association. In the current study, 69 (70\%) of the 99 proteins identified from 1DE had a GRAVY > -0.4 (Supplemental Figure 3), a score indicating the probability for membrane association. Moreover, some alkaline proteins with $P I$ values close to or greater than 10 were separated by 1DE (Supplemental Figure 4), but they could not be detected in a conventional 2DE map.

3.4. Comparison of $2 D E$ and $1 D E$ Datasets. Among the $2 \mathrm{DE}$ dataset $(n=183$ proteins; Table 1$)$ and 1DE dataset 


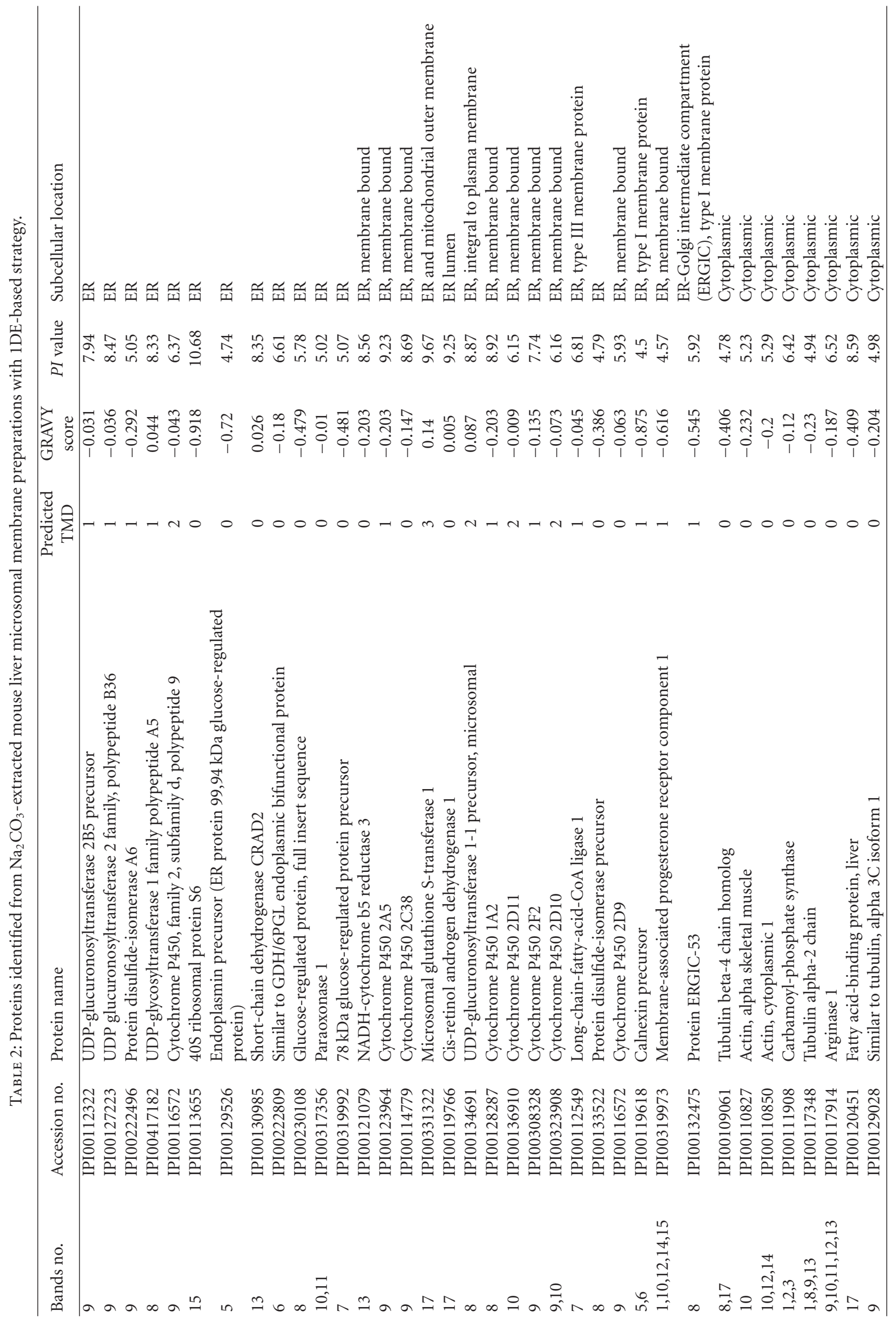




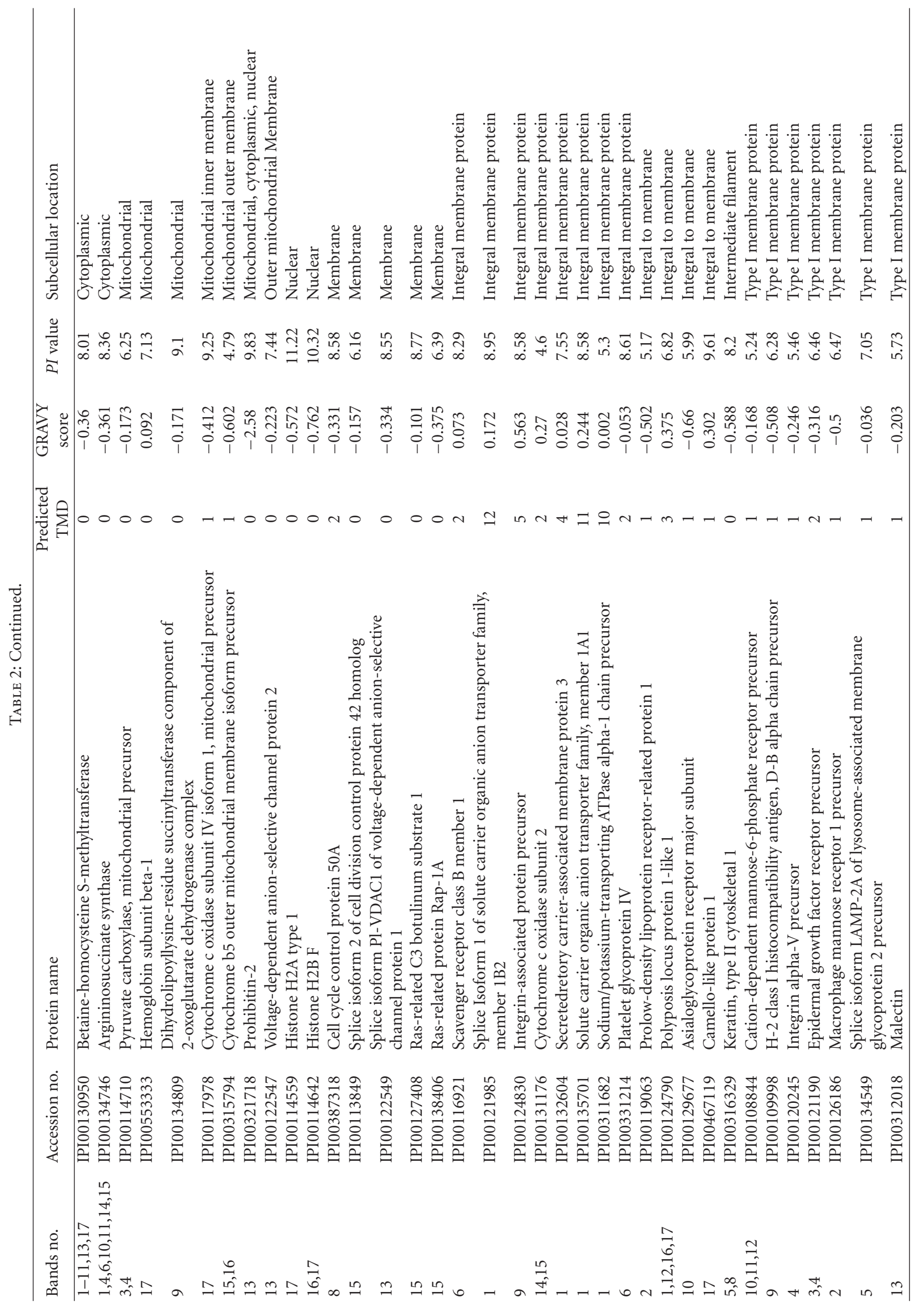




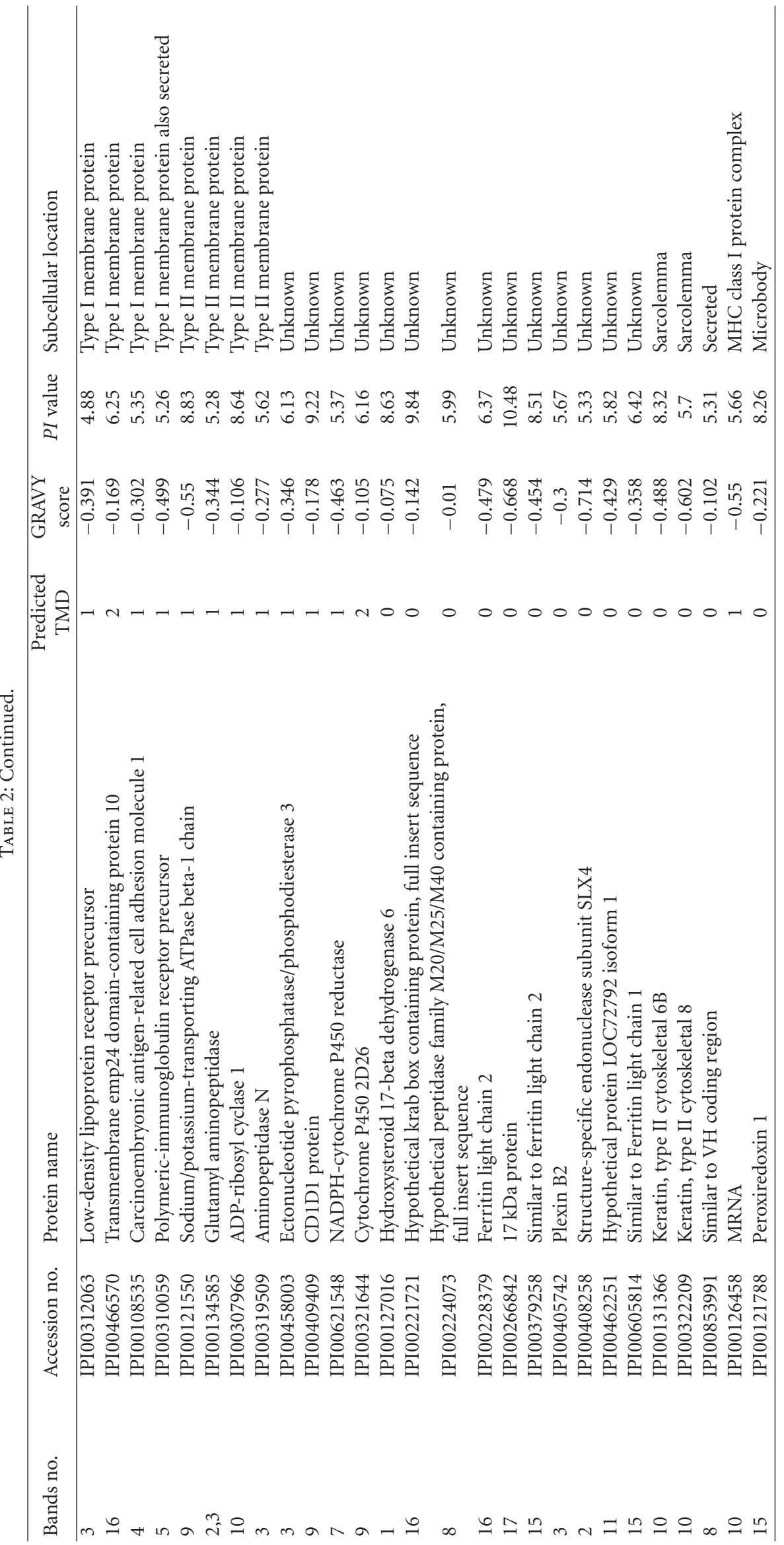




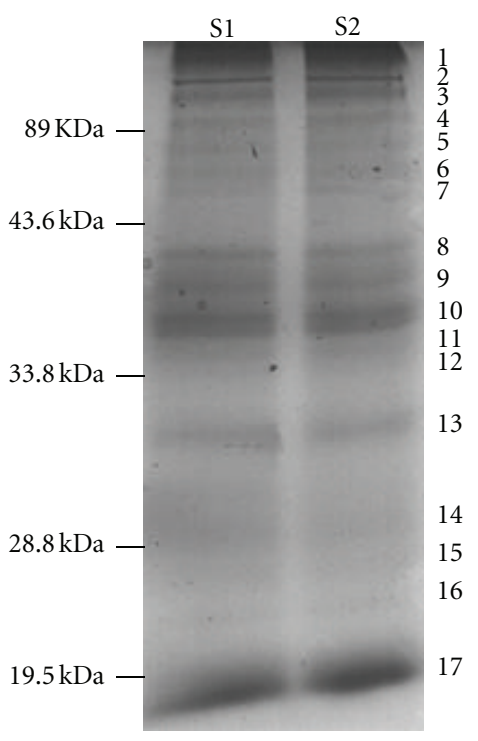

(a)

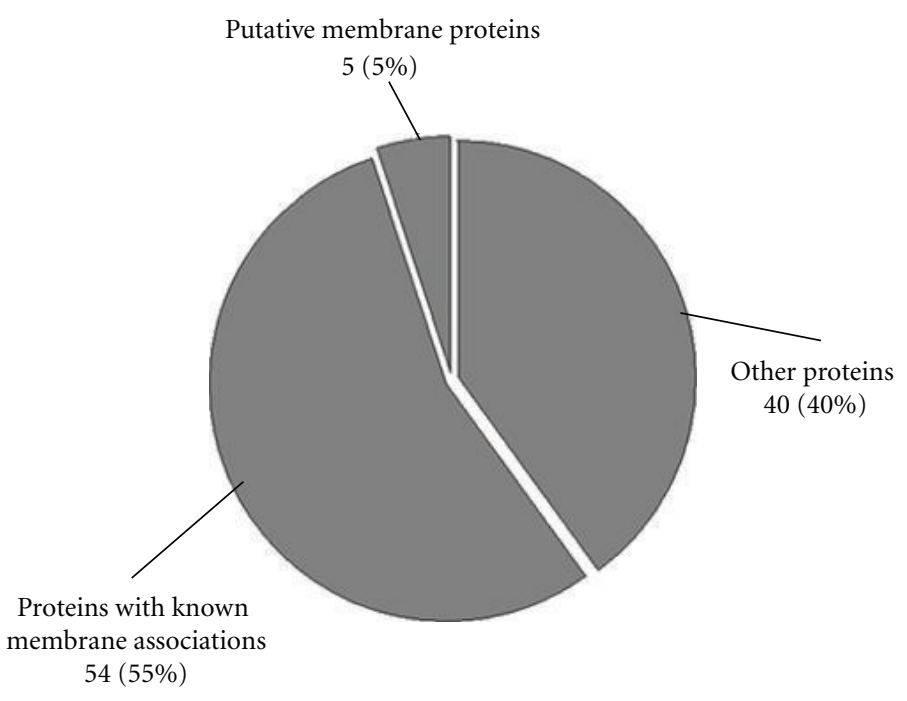

(b)

FIGURE 2: $1 \mathrm{DE}$ pattern and membrane-associated characteristic classification of $\mathrm{Na}_{2} \mathrm{CO}_{3}$-extracted microsomal membrane proteins. (a) $1 \mathrm{DE}$ pattern. Molecular weight markers are shown on the left and bands excised for MS analysis are indicated on the right. Lanes S1 and S2 were loaded with the same protein samples (50 $\mu$ g per lane). (b) Classification via membrane-associated characteristic. The criteria used for this classification were published reports, annotations in the genome database (http://www.uniprot.org/), and predictions for transmembrane regions (http://www.cbs.dtu.dk/services/TMHMM/).

( $n=99$ proteins; Table 2 ), only 23 proteins (Table 3 ) were consistent between $2 \mathrm{DE}$ and $1 \mathrm{DE}$ datasets $(23 \%$ of $1 \mathrm{DE}$ dataset, and $13 \%$ of $2 \mathrm{DE}$ dataset). A total of 259 nonredundant proteins $(n=183+99-23)$ were identified in the microsome fraction through the strategy of combining 2DE with 1DE protein-separation technologies followed by ESI-Q-TOF MS/MS. The microsome consisted of a complex network of continuous membranes including ER, ER-Golgi intermediate complex-also referred to as the vesiculotubular clusters or pre-Golgi intermediates-and the Golgi apparatus [5]. Among those identified proteins, 62 located in ER and Golgi were definitely classified as microsome proteins by annotation in the Swiss-Prot database and the Gene Ontology (GO).

\subsection{Significantly Enriched GO Terms for Mouse Liver Micro-} some Proteins. Biological Networks Gene Ontology [15] and Cytoscape [16] plugins to find statistically overrepresented GO categories were used for the enrichment analysis of our protein dataset. The microsome protein dataset $(n=$ 259, from $1 \mathrm{DE}$ and $2 \mathrm{DE}$ datasets) was compared to a reference set of complete mouse proteome (IPI mouse) that was provided by Biological Networks Gene Ontology. The analysis was done with a hypergeometric test, and all significant $(P<0.01)$ GO terms were selected after correcting for a multiple term testing with a Benjamini and Hochberg false discovery rate. The analysis was performed separately for molecular function, cellular component, and biological process categories, and $\mathrm{x}$-fold enrichment for every overrepresented term in three GO categories was calculated (Supplemental Figure 5). The results showed that the terms were related to mostly catalytic activity in terms of molecular function, including metabolism-related oxidoreductase, hydrolase, and dehydrogenase. Similarly, terms belonging to the cellular component namespace include mitochondrion, ER, and ribosome. Finally, terms from the biological process namespace included metabolic process, localization, transport, and translation. All of the information suggested the main functions and compositions of microsome.

3.6. Significant Enrichment of KEGG Pathway for Mouse Liver Microsome Proteins. Biological pathways analysis based on KEGG pathway database was performed with an analysis toolkit-WebGestalt (http://bioinfo.vanderbilt.edu/ webgestalt/) [17]. This toolkit allowed the functional annotation of gene/protein sets into well-characterized functional signaling pathways (KEGG: http://www.genome.jp/kegg/). In addition, an enrichment score was obtained of the frequency of occurrence of a specific protein (or gene) within any given experimental subset with respect to a species-specific background set. Thus, an enrichment factor (the observed frequency in input set/the expected frequency in background set) was created with a statistical value that indicated that the protein (or gene) was specifically overrepresented in the input dataset. In this current study, all the proteins except $81(n=259-81=178)$ were linked to a total of 99 biological pathways in the KEGG, including metabolic pathway, glycolysis/gluconeogenesis, metabolism of xenobiotics by cytochrome P450, and PPAR signaling pathway. Among those pathways, 34 significantly $(P<0.01)$ enriched biological processes analyzed by 
TABLe 3: Proteins that are consistently present in both $2 \mathrm{DE}$ dataset of microsomal proteins (Table 1 ) and $1 \mathrm{DE}$ dataset of $\mathrm{Na}_{2} \mathrm{CO}_{3}$-extracted microsomal proteins (Table 2).

\begin{tabular}{|c|c|c|c|c|c|}
\hline Accession number & Protein name & Predicted TMD & GRAVY scores & $P I$ value & Location \\
\hline IPI00108454 & Similar to 40 S ribosomal protein S6 & 0 & -0.918 & 10.68 & ER \\
\hline IPI00112322a & UDP-glucuronosyltransferase 2B5 precursor & 1 & -0.031 & 7.94 & ER \\
\hline IPI00129526 & $\begin{array}{l}\text { Endoplasmin precursor (ER protein } 99 \text {, } \\
94 \mathrm{kDa} \text { glucose-regulated protein) }\end{array}$ & 0 & -0.72 & 4.74 & ER \\
\hline IPI00133522 & Protein disulfide-isomerase precursor & 0 & -0.386 & 4.79 & ER \\
\hline IPI00222496 & Protein disulfide isomerase-associated 6 & 1 & -0.292 & 5.05 & ER \\
\hline IPI00230108 & $\begin{array}{l}\text { Glucose-regulated protein, full insert } \\
\text { sequence }\end{array}$ & 0 & -0.479 & 5.78 & ER \\
\hline IPI00319992 & $78 \mathrm{kDa}$ glucose-regulated protein precursor & 0 & -0.481 & 5.07 & ER \\
\hline IPI00331322 & Microsomal glutathione S-transferase 1 & 3 & 0.14 & 9.67 & $\begin{array}{l}\text { ER and mitochondrial } \\
\text { outer membrane }\end{array}$ \\
\hline IPI00319973a & $\begin{array}{l}\text { Membrane-associated progesterone receptor } \\
\text { component } 1\end{array}$ & 1 & -0.616 & 4.57 & ER, membrane bound \\
\hline IPI00109061 & Tubulin beta- 4 chain homolog & 0 & -0.406 & 4.78 & Cytoplasmic \\
\hline IPI00110827 & Actin, alpha skeletal muscle & 0 & -0.232 & 5.23 & Cytoplasmic \\
\hline IPI00110850 & Actin, cytoplasmic 1 & 0 & -0.2 & 5.29 & Cytoplasmic \\
\hline IPI00111908 & Predicted: carbamoyl-phosphate synthetase 1 & 0 & -0.12 & 6.42 & Cytoplasmic \\
\hline IPI00117348 & Tubulin alpha- 2 chain & 0 & -0.23 & 4.94 & Cytoplasmic \\
\hline IPI00117914 & Arginase 1 & 0 & -0.187 & 6.52 & Cytoplasmic \\
\hline IPI00134746 & Argininosuccinate synthase & 0 & -0.361 & 8.36 & Cytoplasmic \\
\hline IPI00117978 & $\begin{array}{l}\text { Cytochrome c oxidase subunit IV isoform } 1 \text {, } \\
\text { mitochondrial precursor }\end{array}$ & 1 & -0.412 & 9.25 & $\begin{array}{l}\text { Mitochondrial inner } \\
\text { membrane }\end{array}$ \\
\hline IPI00315794 & $\begin{array}{l}\text { Cytochrome b5 outer mitochondrial } \\
\text { membrane isoform precursor }\end{array}$ & 1 & -0.602 & 4.79 & $\begin{array}{l}\text { Mitochondrial outer } \\
\text { membrane }\end{array}$ \\
\hline IPI00122547 & $\begin{array}{l}\text { Voltage-dependent anion-selective channel } \\
\text { protein } 2\end{array}$ & 0 & -0.223 & 7.44 & $\begin{array}{l}\text { Outer mitochondrial } \\
\text { membrane }\end{array}$ \\
\hline IPI00124790 & Polyposis locus protein 1-like 1 & 3 & 0.375 & 6.82 & Integral to membrane \\
\hline IPI00138406 & Ras-related protein Rap-1A & 0 & -0.375 & 6.39 & Membrane \\
\hline IPI00121788 & Peroxiredoxin 1 & 0 & -0.221 & 8.26 & Microbody \\
\hline IPI00131366 & Keratin, type II cytoskeletal 6B & 0 & -0.488 & 8.32 & Sarcolemma \\
\hline
\end{tabular}

${ }^{a}$ Membrane proteins with one or more predicted trans-membrane origins or validated by references.

WebGestalt were obtained (Figure 3). Those biological processes were involved in cell metabolism, benzoate degradation, metabolism of xenobiotics, ribosome, biosynthesis, signaling pathway, and oxidative stress. Those results are known to be related to microsome.

To ascertain the coverage of our dataset with the enriched pathways or biological processes, the KEGG search service was used to map our dataset on KEGG pathways. Two of the aforementioned enriched KEGG pathways (metabolism of xenobiotics and ribosome) were related to the well-known function and composition of the microsome (Figure 4). Enzyme Commission numbers (EC no., e.g, 1.14.14.1) are used to represent enzymes in metabolism. Highlighted in green background are known mouse enzymes annotated in the KEGG database and the red boxed are enzymes in our dataset (Figure 4(a)). All enzymes $(n=9)$ that played a key role in every pathway of metabolism of xenobiotics were included in our dataset (Table 4). Thirteen proteins from large and small subunits of ribosome were also found in our dataset (Table 4) and are indicated with a red box
(Figure 4(b)). These proteins interact physically with each other and form a large protein complex-the ribosome. All the identified proteins that are involved in those two pathways are summarized in Table 4, including their KEGG pathway, protein ID, and protein name.

\section{Discussion}

Proteome analysis of the cell membrane-bound organelles is a daunting task mainly because of (a) isolation of membrane that is free from nonconstituents and (b) solubilization of membrane proteins in a manner amenable to isoelectric focusing [10]. 2DE is an effective tool to survey biological complexity at the molecular level and provides a systematic and comprehensive study of the proteins. However, because of the PI value range limited by the IPG strip and the high dependence on sample preparation, some problems exist for the available $2 \mathrm{DE}$ protocols to resolve membrane-associated proteins $[10,22]$. Therefore, in the current study, the whole 


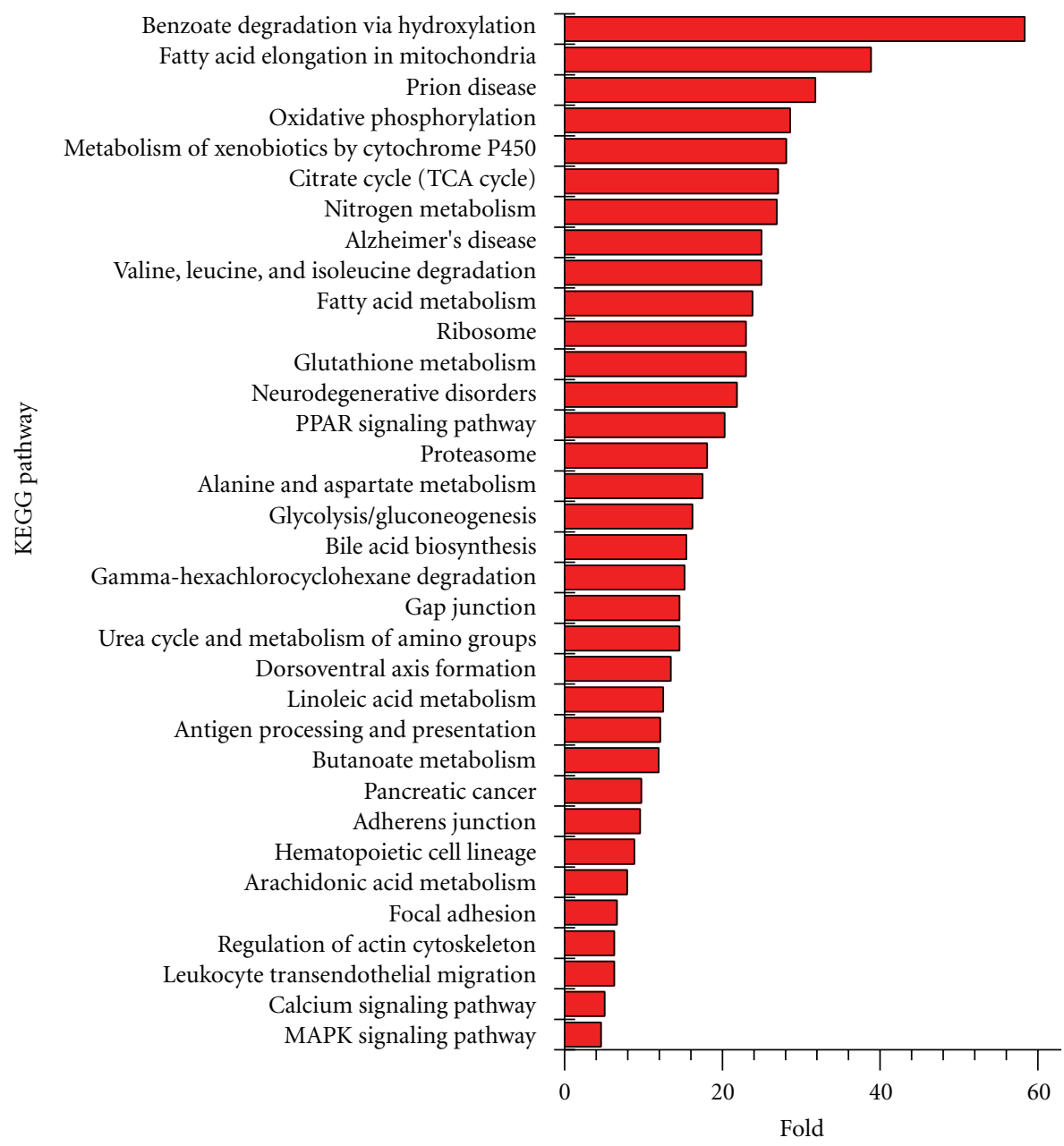

FIGURE 3: Significantly enriched KEGG pathways for mouse liver microsome proteins $(n=259)$ that were derived from $1 \mathrm{DE}$ and $2 \mathrm{DE}$ strategies. KEGG pathway enrichment analysis was performed using WebGestalt. The pathways having enrichment $(P<0.01)$ are presented. For each KEGG pathway, the bar shows the $\mathrm{x}$-fold enrichment of the pathway in our dataset.

microsome lysate was arrayed with 2DE, and the membrane fraction of microsomes purified by the carbonate procedure was separated with $1 \mathrm{DE}$. The complementary 2DE and 1DE approaches provided a much wider coverage of microsome proteome.

Hydrophobicity and relatively low abundance causes a challenge for proteomic technology to separate and identify membrane proteins. The hydrophobicity of proteins is frequently expressed as GRAVY scores (http://us.expasy.org/ tools/protparam.html). A calculated GRAVY score of up to 0.4 indicates a hydrophobic protein, suggesting a membrane association [21]. In the current study, 69 (70\%) of the 99 proteins identified from 1DE had a GRAVY > -0.4 (Supplemental Figure 3), indicating the probability for membrane association [21]. As shown in Supplemental Figure 4, some alkaline proteins with $P I$ values close to or greater than 10 were separated by $1 \mathrm{DE}$; they could not be detected in conventional 2DE map. Only 23 proteins were found to be consistent between 2DE and 1DE datasets with 6 proteins classified as membrane proteins (Table 3 ). All these results indicate that $1 \mathrm{DE}$ is a potent supplement to $2 \mathrm{DE}$, and the combination of the two approaches is necessary in protein profiling of microsomes.

Microsome-sealed vesicles could be converted into flat membrane sheets with cisternal contents that were released effectively with the treatment solution ( $100 \mathrm{mM} \mathrm{Na}_{2} \mathrm{CO}_{3}$; $\left.0^{\circ} \mathrm{C}\right)$. It appears to be as effective as the low detergent procedure in selectively releasing microsomal content. In the current study, some proteins that were identified from $\mathrm{Na}_{2} \mathrm{CO}_{3}$-extracted fraction were classified as membrane associated mainly based on published reports, even though their predicted transmembrane domains (TMDs) did not suggest a membrane origin. The observations point out the fact that structure alone may not be the deciding factor, as far as the association of proteins with cell membrane is concerned. First, the proteins may be bound to the membrane simply to perform their functional obligations. Consequently, they could become part of complexes involving membrane proteins and may not depart from them easily under the conditions of sample preparation. For example, many enzymes were identified in the extracted membrane fraction, such as Cis-retinol androgen dehydrogenase 1 


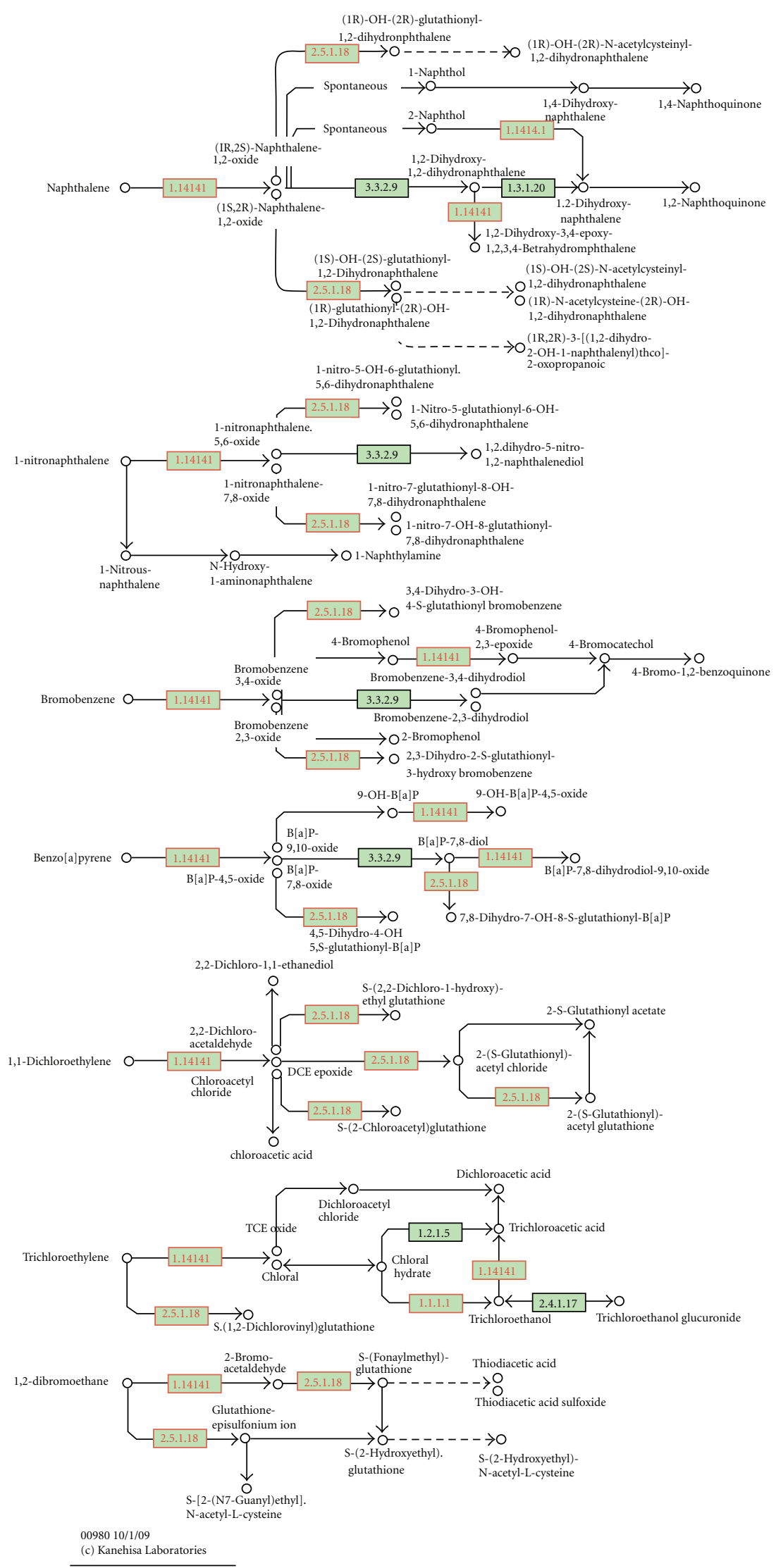

(a)

Figure 4: Continued. 


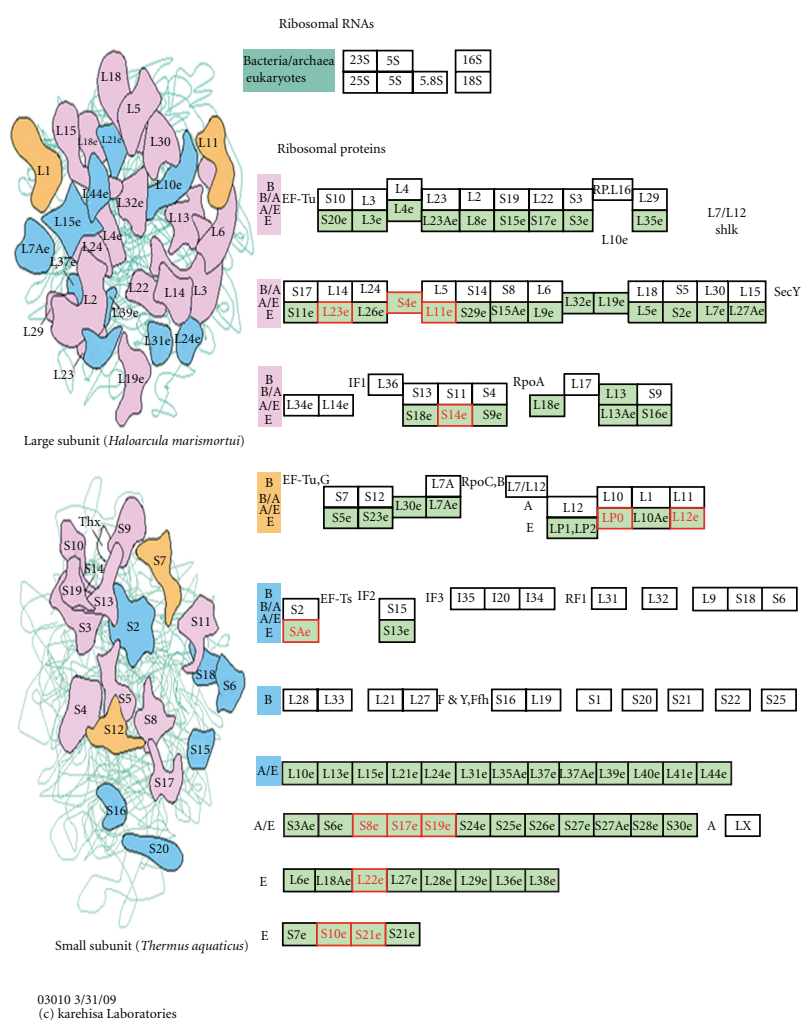

(b)

FIGURE 4: Metabolism of xenobiotics by cytochrome P450 pathway, and ribosome map views of identified proteins. The two enriched metabolic pathway maps were generated by KEGG, which incorporated the proteomic data into the KEGG pathway maps. All of the genes in mouse are colored; the genes contained in the protein dataset are red.

(short-chain dehydrogenase family). It is anchored to the ER membrane facing the cytoplasm by an N-terminal signaling sequence of 22 residues and takes part in the membraneassociated retinoid metabolism [23], so is fatty acid-binding protein, which participates in the palmitic acid or retinylester metabolism that is incorporated in microsomal membranes [24] and the free fatty acid transferation to the membrane. Second, some truly cytosolic proteins may simply integrate with membrane vesicles during the sonication process and become difficult to remove by the extraction methods [25]. Studies [5] have demonstrated that hepatic microsomes are derived from the ER and other cell organelles. The ER represents a membrane tubular network that crosses the cytoplasm from the nucleus membrane to the plasma membrane. Moreover, some proteins perform their functions between cytoplasm and ER, such as fatty-acid-binding proteins [26]. From this point of view, taking all of the portions into account, $60 \%-70 \%$ of the proteins identified can be regarded as microsome proteins in this research. A part $(\sim 15 \%)$ of identified proteins did not have unambiguous locations in published reports or annotations in the genome database. This current study provides information relevant to subcellular locations of these proteins for subsequent studies.

Two datasets from 1DE and 2DE are part of the complete protein composition of microsomes. A bioinformatics analysis of the two datasets combined offers more information. For an overview of the proteomic data and comprehending their biological importance, biological networks GO (BinGO) (http://www.psb.ugent.be/cbd/papers/ BiNGO/index.html) was used to identify GO-category significant enrichment with all the identified proteins. BiNGO is a plugin for Cytoscape, which is an open source bioinformatics software platform to visualize and integrate molecular interaction networks. BinGO maps the predominant functional themes of a given gene set on the GO hierarchy. Of the 259 target proteins and direct partners analyzed, 182 target proteins linked to one or more GO terms. GO-term enrichment analysis revealed that the most highly represented GO terms in the cellular GO category component were organelles such as ER, mitochondrial, and organelle membrane. An analysis of the proteins that were identified according to their potential roles in biological processes indicated that the proteins were mainly involved in metabolic process, localization, transport, and translation. All the results were highly statistically significant.

The KEGG pathway database integrates current knowledge on molecular interaction networks in biological processes. To gain a broad understanding of our dataset, WebGestalt (a web-based gene set analysis toolkit) was used to map the identified proteins to KEGG pathways. The results showed that 112 of the total proteins were associated with one or more KEGG pathways. Meanwhile, 97 of 112 target proteins (87\%) fell into 34 KEGG pathways; 
TABLe 4: Proteins involved in KEGG pathways. (a) Metabolism of xenobiotics. (b) Ribosome.

\begin{tabular}{|c|c|c|c|c|}
\hline \multicolumn{2}{|c|}{ KEGG pathway } & \multirow{2}{*}{$\begin{array}{c}\text { Protein ID } \\
\text { IPI00128287 }\end{array}$} & \multirow{2}{*}{$\begin{array}{l}\text { Protein name } \\
\text { Cytochrome P450 1A2 }\end{array}$} & \multirow{2}{*}{$\begin{array}{c}\text { MS-identified proteins } \\
+\end{array}$} \\
\hline $\begin{array}{l}\text { A. Metabolism of } \\
\text { exnobiotics }\end{array}$ & EC:1.14.14.1 & & & \\
\hline & & IPI00123964 & Cytochrome P450 2A5 & + \\
\hline & & IPI00116572 & Cytochrome P450 2D9 & + \\
\hline & & IPI00323908 & Cytochrome P450 2D10 & + \\
\hline & & IPI00321644 & Cytochrome P450 2D26 & + \\
\hline & & IPI00114779 & Cytochrome P450 2C38 & + \\
\hline & & IPI00308328 & Cytochrome P450 2F2 & + \\
\hline & EC:2.5.1.18 & IPI00331322 & Microsomal glutathione S-transferase 1 & + \\
\hline & EC:1.1.1.1 & IPI00221400 & Alcohol dehydrogenase A chain & + \\
\hline \multirow[t]{13}{*}{ B. Ribosome } & Small subunit & IPI00135640 & $26 S$ protease regulatory subunit 8 & + \\
\hline & & IPI00125971 & $26 \mathrm{~S}$ protease regulatory subunit $\mathrm{S} 10 \mathrm{~B}$ & + \\
\hline & & IPI00331092 & $40 \mathrm{~S}$ ribosomal protein $\mathrm{S} 4, \mathrm{X}$ isoform & + \\
\hline & & IPI00116908 & Similar to 40 s ribosomal protein $\mathrm{S} 12$ & + \\
\hline & & IPI00322562 & 40 S ribosomal protein $\mathrm{S} 14$ & + \\
\hline & & IPI00465880 & 40 S ribosomal protein $\mathrm{S} 17$ & + \\
\hline & & IPI00113241 & 40 S ribosomal protein $\mathrm{S} 19$ & + \\
\hline & & IPI00123604 & 40 S ribosomal protein SA & + \\
\hline & & IPI00314950 & $60 \mathrm{~S}$ acidic ribosomal protein $\mathrm{P} 0$ & + \\
\hline & Large subunit & IPI00331461 & $60 S$ ribosomal protein L11 & + \\
\hline & & IPI00849793 & 60 S ribosomal protein $\mathrm{L} 12$ & + \\
\hline & & IPI00222546 & 60 S ribosomal protein L22 & + \\
\hline & & IPI00139780 & 60 S ribosomal protein L23 & + \\
\hline
\end{tabular}

they were specifically enriched $(P<0.01)$ compared to statistical expectations. Pathways that are involved in benzoate degradation, metabolism of xenobiotic, glutamate metabolism, and cysteine metabolism were among the most enriched biologically. This finding was consistent with the fact that microsomes were used to investigate the metabolism of compounds and to examine drug-drug interaction by in vitro studies.

Collectively, the bioinformatics analysis via enrichment analysis of GO annotation and KEGG pathways derived meaning from the proteomic data and assisted in the understanding of the function of liver at the subcellular level.

Novelty and Limitation. Mammalian liver microsome proteomes have been studied by several groups [18-20]. Comparison of the current study with the literature data [18-20] was shown in Tables 5 and 6. Zgoda et al. [18] studied differential ultracentrifugation-separated mouse liver microsome proteome; $2 \mathrm{DE}$ and silver stain yielded 1,100 protein spots, and 138 proteins contained in 2D gel spots were identified with peptide mass fingerprint (PMF). Zgoda et al. [19] also studied differential ultracentrifugation-separated mouse liver microsome proteome with $1 \mathrm{DE}$ and MS/MS; 519 proteins were identified including $138(138 / 519=27 \%)$ predicted membrane proteins. Gilchrist et al. [20] used 1DE and MS/MS to analyze rat ER and Golgi that were separated with differential ultracentrifugation and density gradient centrifugation; 832 ER proteins were identified including $183(183 / 832=22 \%)$ membrane proteins. This current study combined differential ultracentrifugation and sucrose gradient centrifugation to prepare mouse liver microsomes; 2DE and Coomassie brilliant blue stain yielded 514 protein spots, and 183 proteins were identified with MS/MS from 204 excised gel spots, including $41(41 / 183=22 \%)$ membrane proteins. $\mathrm{Na}_{2} \mathrm{CO}_{3}$ was used to further extract membrane proteins from isolated microsomes; 1DE and Coomassie brilliant blue stain yield 17 protein bands, and 99 proteins were identified with MS/MS from those 17 protein bands, including $54(54 / 99=55 \%)$ membrane proteins. A total of 259 nonredundant proteins were identified including $62(62 / 259=24 \%)$ membrane proteins. Compared to the documented data [18-20], the novelty of this current study is that the carbonate method significantly increased the identification rate of microsomal membrane proteins, that some proteins and functional annotations from this current study have not been identified in other literature, which expanded and enriched the documented data, and that the established analysis system and data will benefit the discovery of liver disease-related microsomal membrane proteins. Meanwhile, we also noted that the current study had a relatively low coverage ( $n=259$ proteins) of mouse liver microsome proteome relative to the documented data $(n=519$ proteins [19] and 832 proteins [20]), which might be derived from several factors: (i) inconsistent protein-extracted procedures 


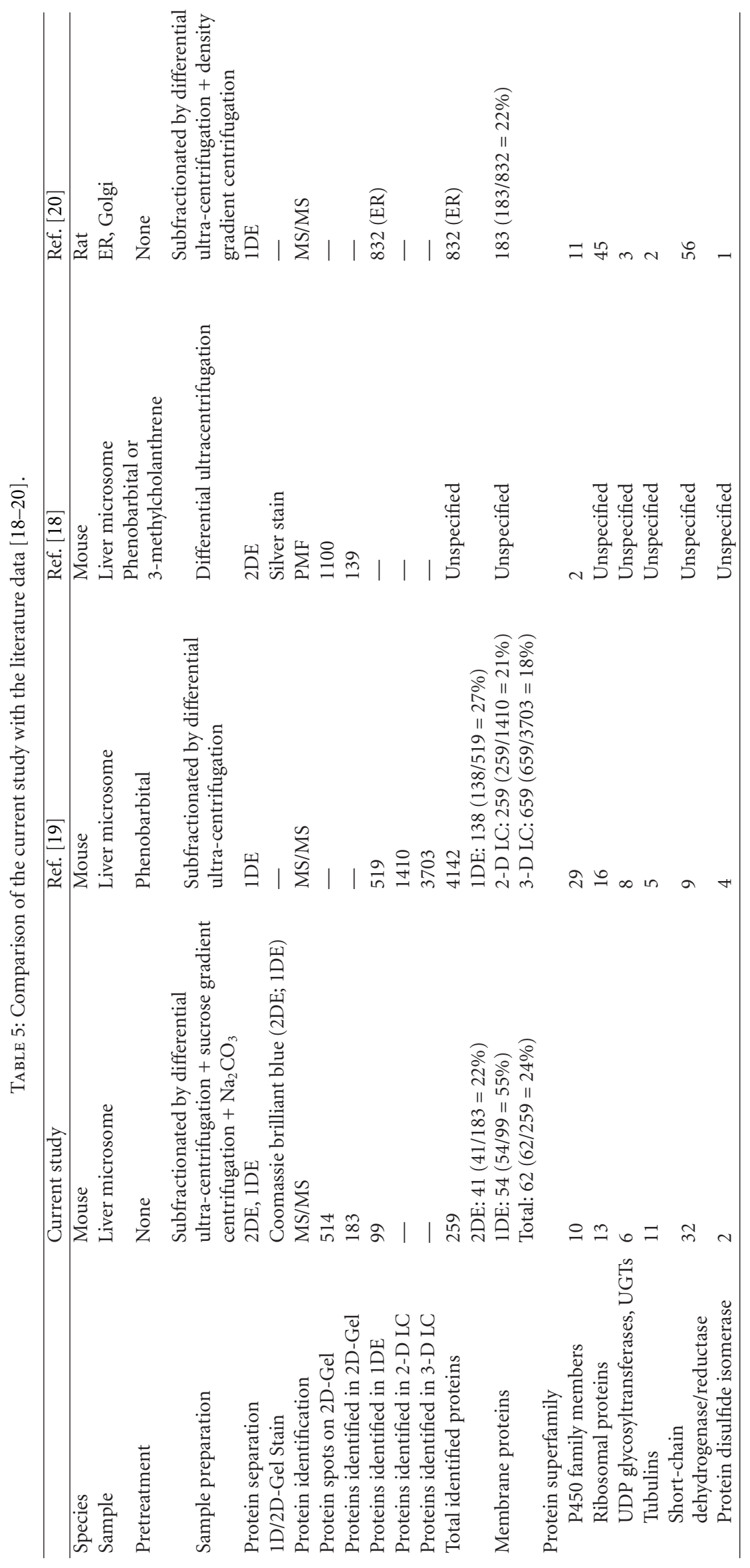




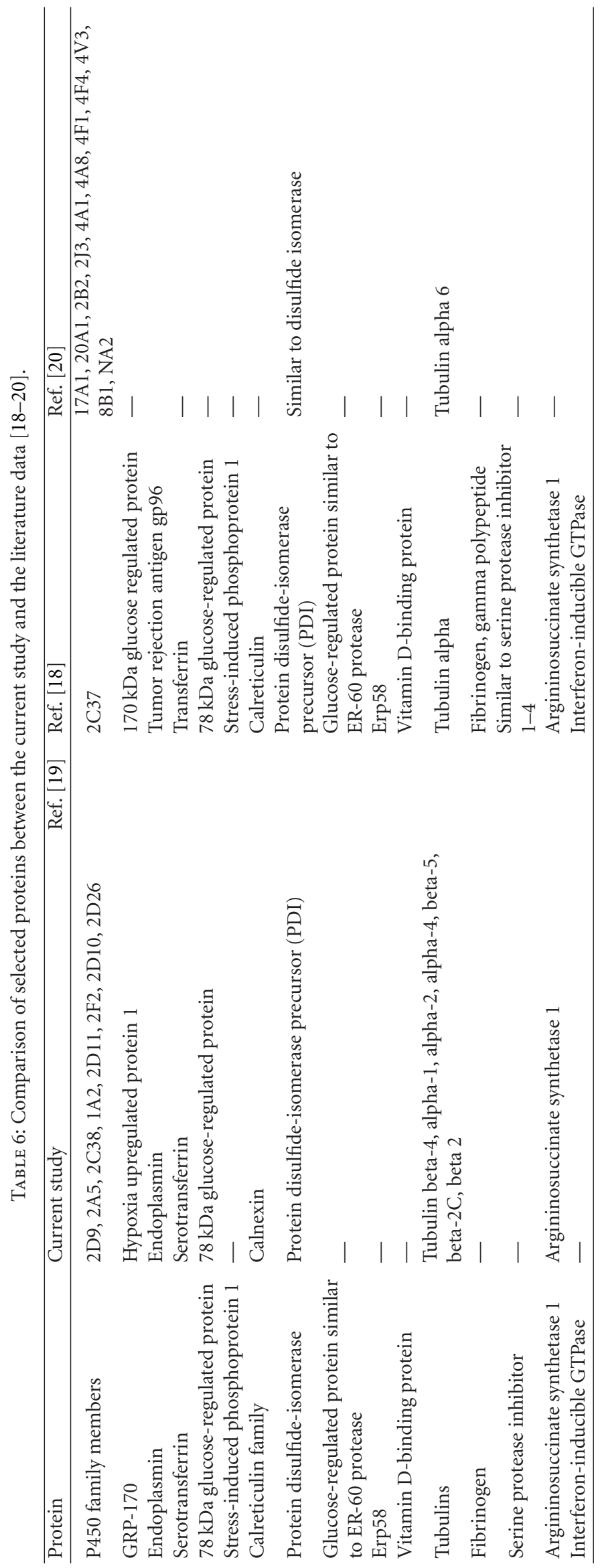




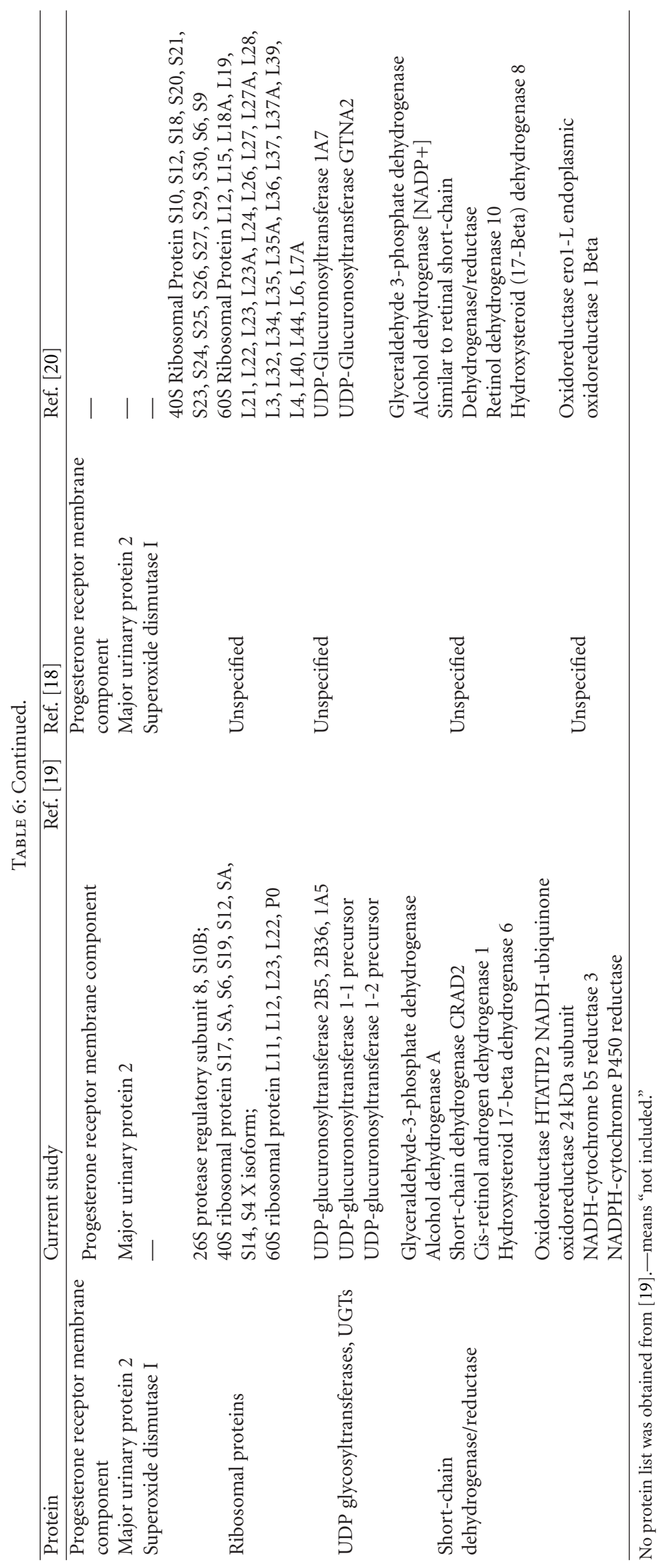


and protein-stained methods were used, (ii) only part of 2D gel spots were excised to identify proteins, (iii) only visualized 1D gel bands (not the entire 1D gel lane) were used for protein identification, (iv) MS/MS (not PMF) was used to identify 2D gel proteins, (v) different sensitivity mass spectrometers were used, (vi) different parameters were used to search protein database. The use of 2D/3D LC-MS/MS [19] and carbonate extraction of isolated microsomes would significantly improve the coverage of microsomal membrane proteome.

\section{Conclusions}

The preparation of liver microsomes was optimized. The data presented here demonstrated that $1 \mathrm{DE}$ and 2DE are complementary approaches to analyze the intracellular microsomes that contain considerable numbers of highly hydrophobic membrane proteins. An integrated bioinformatics analysis of all of the microsome proteins identified with $1 \mathrm{DE}$ and 2DE can provide a relatively complete understanding of the protein composition and cellular function of the target microsome organelles. The information presented here will be useful for successful analysis of other membranous organelles. Our data will assist in understanding the function of liver and are an important reference for subsequent analysis of liver disease-related microsome proteins for biomarker discovery and mechanism clarification of a liver disease.

\section{Abbreviations}

ACN: Acetonitrile

BinGO: Biological Networks Gene Ontology

DTT: Dithiothreitol

1DE: One-dimensional gel electrophoresis

2DE: Two-dimensional gel electrophoresis

ER: Endoplasmic reticulum

GO: Gene ontology

GRAVY: Grand average of hydropathy

HLPP: Human Liver Proteome Project

IEF: Isoelectric focusing

KEGG: Kyoto Encyclopedia of Genes and Genomes

LC: Liquid chromatography

MS: $\quad$ Mass spectrometry

MS/MS: Tandem mass spectrometry

Q-TOF: Quadrupole-time of flight

RP: $\quad$ Reverse phase

TMD: Transmembrane domains.

\section{Acknowledgments}

This work was supported by China National Haman Liver Proteome Project (Grant no. 2004 BA711A18) and The National Basic Research Program of China (Grant No. 2011CB910704).

\section{References}

[1] F. He, "Human liver proteome project: plan, progress, and perspectives," Molecular and Cellular Proteomics, vol. 4, no. 12, pp. 1841-1848, 2005.

[2] E. Jung, M. Heller, J. C. Sanchez, and D. F. Hochstrasser, "Proteomics meets cell biology: the establishment of subcellular proteomes," Electrophoresis, vol. 21, no. 16, pp. 3369-3377, 2000.

[3] S. W. Taylor, E. Fahy, and S. S. Ghosh, "Global organellar proteomics," Trends in Biotechnology, vol. 21, no. 2, pp. 82-88, 2003.

[4] F. S. Heinemann and J. Ozols, "Isolation and structural analysis of microsomal membrane proteins," Frontiers in Bioscience, vol. 3, pp. 483-493, 1998.

[5] D. M. Wong and K. Adeli, "Microsomal proteomics," Methods in Molecular Biology, vol. 519, pp. 273-289, 2009.

[6] K. Okuzawa, B. Franzen, J. Lindholm et al., "Characterization of gene expression in clinical lung cancer materials by two-dimensional polyacrylamide gel electrophoresis," Electrophoresis, vol. 15, no. 3-4, pp. 382-390, 1994.

[7] P. Chen, L. Zhang, X. Li et al., "Evaluation of strategy for analyzing mouse liver plasma membrane proteome," Science in China Series C, vol. 50, no. 6, pp. 731-738, 2007.

[8] N. Galeva and M. Altermann, "Comparison of onedimensional and two-dimensional gel electrophoresis as a separation tool for proteomic analysis of rat liver microsomes: cytochromes $\mathrm{P} 450$ and other membrane proteins," Proteomics, vol. 2, no. 6, pp. 713-722, 2002.

[9] I. P. Kanaeva, N. A. Petushkova, A. V. Lisitsa et al., "Proteomic and biochemical analysis of the mouse liver microsomes," Toxicology In Vitro, vol. 19, no. 6, pp. 805-812, 2005.

[10] V. Santoni, M. Molloy, and T. Rabilloud, "Membrane proteins and proteomics: un amour impossible?" Electrophoresis, vol. 21, no. 6, pp. 1054-1070, 2000.

[11] G. Friso, L. Giacomelli, A. J. Ytterberg et al., "In-depth analysis of the thylakoid membrane proteome of Arabidopsis thaliana chloroplasts: new proteins, new functions, and a plastid proteome database," Plant Cell, vol. 16, no. 2, pp. 478499, 2004

[12] Y. Fujiki, A. L. Hubbard, S. Fowler, and P. B. Lazarow, "Isolation of intracellular membranes by means of sodium carbonate treatment: application to endoplasmic reticulum," Journal of Cell Biology, vol. 93, no. 1, pp. 97-102, 1982.

[13] S. Fleischer and M. Kervina, "Subcellular fractionation of rat liver," Methods in Enzymology, vol. 31, pp. 6-41, 1974.

[14] G. Candiano, M. Bruschi, L. Musante et al., "Blue silver: a very sensitive colloidal Coomassie G-250 staining for proteome analysis," Electrophoresis, vol. 25, no. 9, pp. 1327-1333, 2004.

[15] S. Maere, K. Heymans, and M. Kuiper, "BiNGO: a cytoscape plugin to assess overrepresentation of Gene Ontology categories in Biological Networks," Bioinformatics, vol. 21, no. 16, pp. 3448-3449, 2005.

[16] P. Shannon, A. Markiel, O. Ozier et al., "Cytoscape: a software environment for integrated models of biomolecular interaction networks," Genome Research, vol. 13, no. 11, pp. 2498-2504, 2003.

[17] B. Zhang, S. Kirov, and J. Snoddy, "WebGestalt: an integrated system for exploring gene sets in various biological contexts," Nucleic Acids Research, vol. 33, no. 2, pp. W741-W748, 2005.

[18] V. Zgoda, O. Tikhonova, A. Viglinskaya, M. Serebriakova, A. Lisitsa, and A. Archakov, "Proteomic profiles of induced hepatotoxicity at the subcellular level," Proteomics, vol. 6, no. 16, pp. 4662-4670, 2006. 
[19] V. G. Zgoda, S. A. Moshkovskii, E. A. Ponomarenko et al., "Proteomics of mouse liver microsomes: performance of different protein separation workflows for LC-MS/MS," Proteomics, vol. 9, no. 16, pp. 4102-4105, 2009.

[20] A. Gilchrist, C. E. Au, J. Hiding et al., "Quantitative proteomics analysis of the secretory pathway," Cell, vol. 127, no. 6, pp. 1265-1281, 2006.

[21] J. Kyte and R. F. Doolittle, "A simple method for displaying the hydropathic character of a protein," Journal of Molecular Biology, vol. 157, no. 1, pp. 105-132, 1982.

[22] C. Adessi, C. Miege, C. Albrieux, and T. Rabilloud, "Twodimensional electrophoresis of membrane proteins: a current challenge for immobilized pH gradients," Electrophoresis, vol. 18, no. 1, pp. 127-135, 1997.

[23] M. Zhang, P. Hu, and J. L. Napoli, "Elements in the Nterminal signaling sequence that determine cytosolic topology of short-chain dehydrogenases/reductases: studies with retinol dehydrogenase type 1 and cis-retinol/androgen dehydrogenase type 1," Journal of Biological Chemistry, vol. 279, no. 49, pp. 51482-51489, 2004.

[24] R. Zanetti and A. Catala, "Interaction of fatty acid binding protein with microsomes: removal of palmitic acid and retinyl esters," Archives Internationales de Physiologie et de Biochimie, vol. 98, no. 4, pp. 173-177, 1990.

[25] G. Friso and L. Wikström, "Analysis of proteins from membrane-enriched cerebellar preparations by two-dimensional gel electrophoresis and mass spectrometry," Electrophoresis, vol. 20, no. 4-5, pp. 917-927, 1999.

[26] S. Stan, M. Lambert, E. Delvin et al., "Intestinal fatty acid binding protein and microsomal triglyceride transfer protein polymorphisms in French-Canadian youth," Journal of Lipid Research, vol. 46, no. 2, pp. 320-327, 2005. 

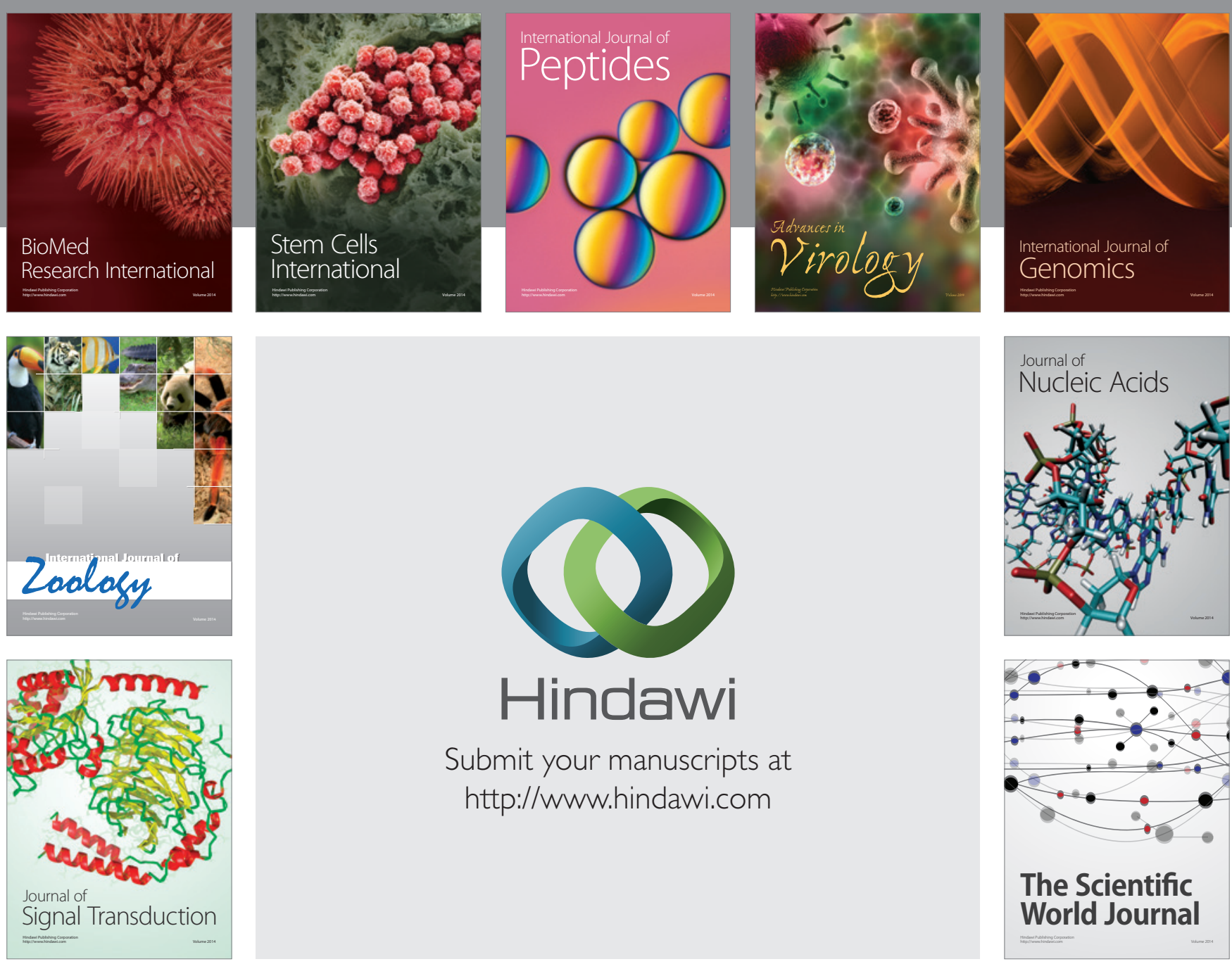

Submit your manuscripts at

http://www.hindawi.com
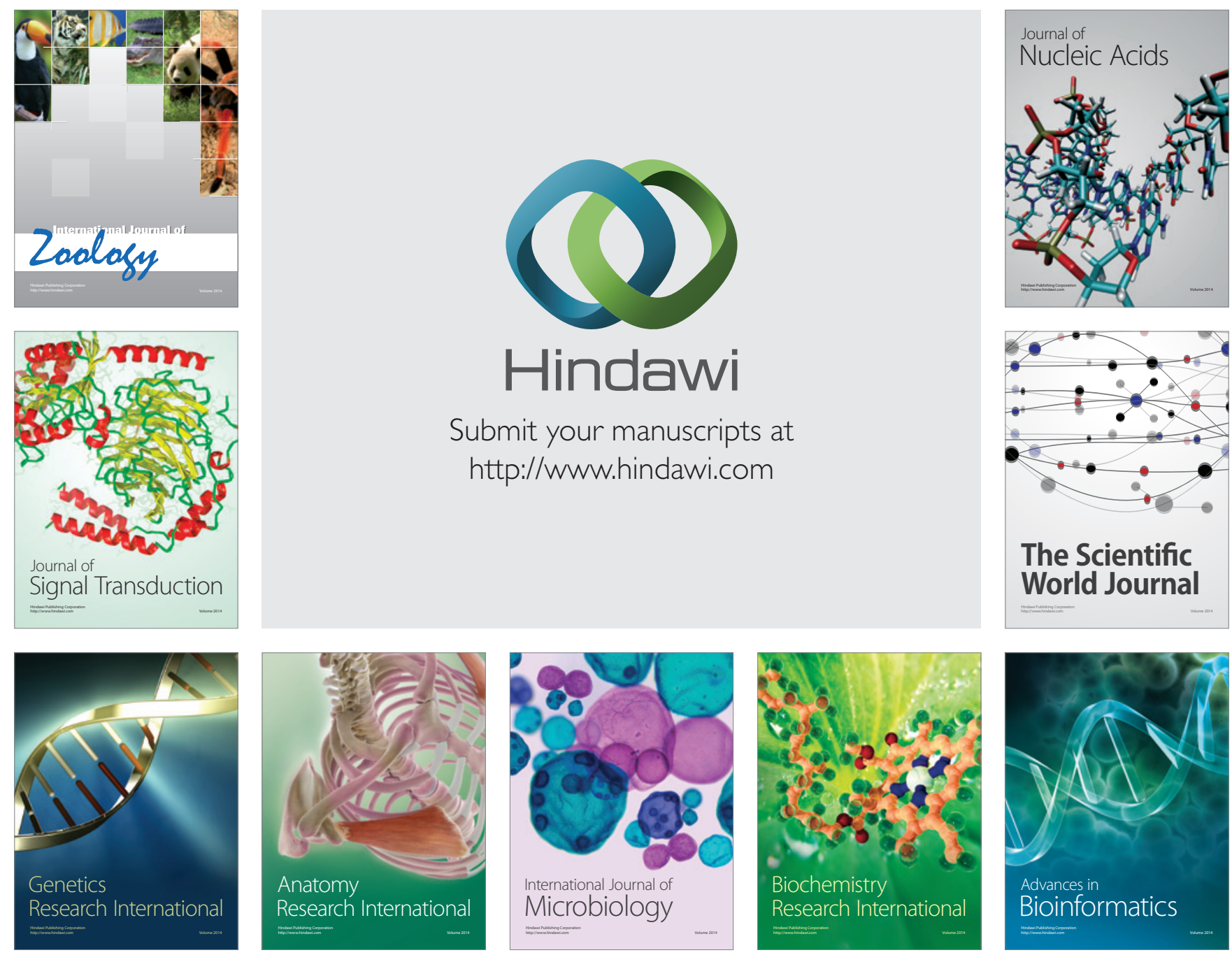

The Scientific World Journal
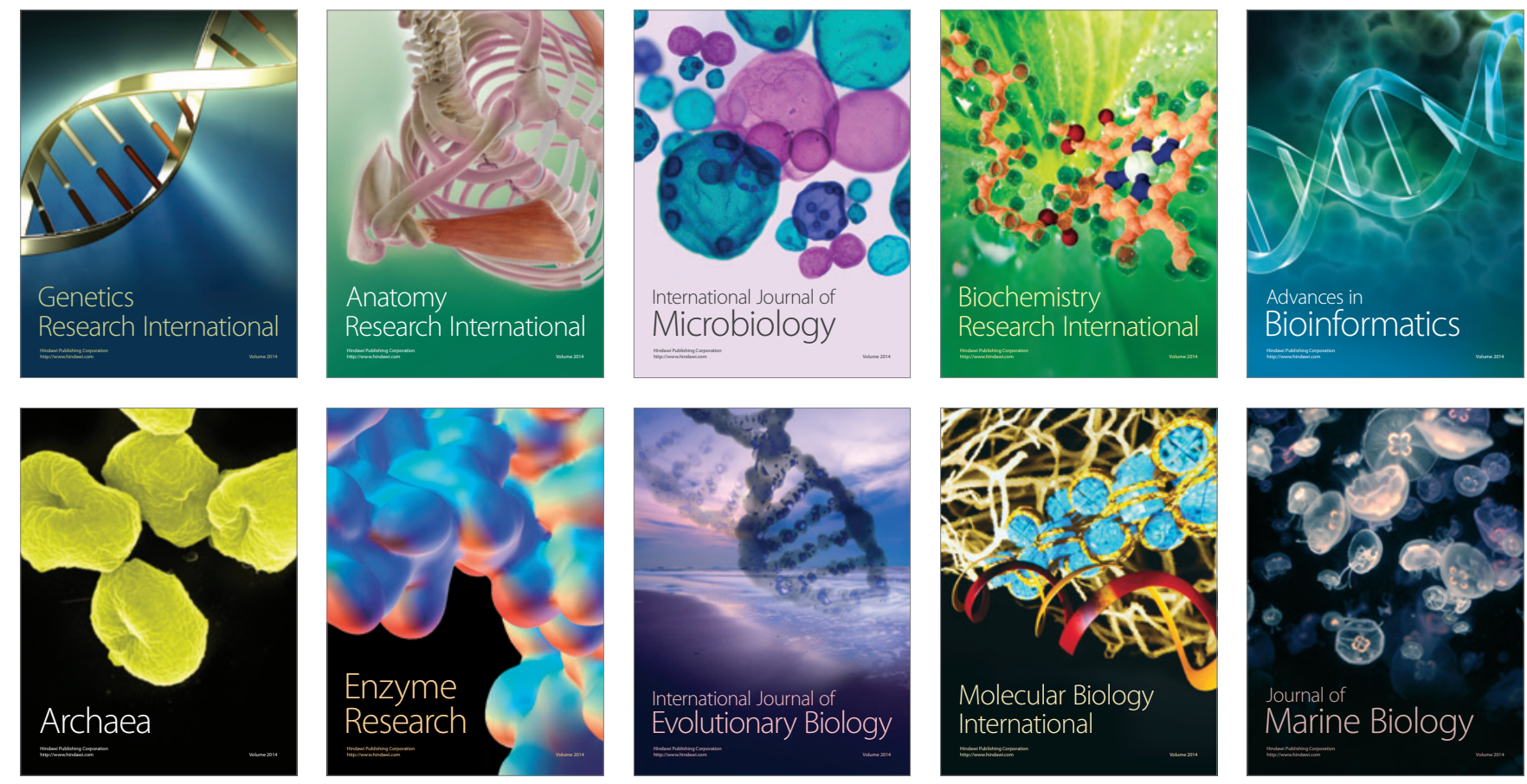